\title{
PATRONES DE RIQUEZA ESPECÍFICA DE LAS FAMILIAS MELASTOMATACEAE Y RUBIACEAE EN LA CORDILLERA ORIENTAL, COLOMBIA, NORTE DE LOS ANDES Y CONSIDERACIONES PARA LA CONSERVACIÓN
}

\section{Species richness patterns of Melastomataceae and Rubiaceae in the Eastern Cordillera of Colombia, Northern Andes: conservation implications}

Palabras clave: Colombia, riqueza de especies, recambio de especies.

Key words: Colombia, species richness, species turnover.

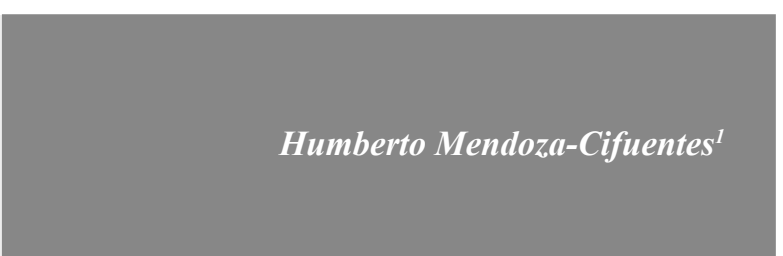

\section{RESUMEN}

De acuerdo con los inventarios estandarizados de las familias Melastomataceae y Rubiaceae a lo largo de la Cordillera Oriental de Colombia, se evaluó el comportamiento de la riqueza específica en los gradientes altitudinal y latitudinal. El inventario realizado representa el 30 y $23 \%$ de la totalidad de especies de Melastomataceae y Rubiaceae conocidas para Colombia. Las tendencias altitudinales encontradas son: (1) la riqueza disminuyó con el incremento de la altitud, pero Rubiaceae decreció más que Melastomataceae; (2) se encontraron altos valores del recambio de especies en el gradiente altitudinal, lo cual indica que en $1000 \mathrm{~m}$ altitudinales la composición de las dos familias cambia completamente. Las tendencias latitudinales encontradas fueron (1) en la vertiente oriental se encontró un incremento de la riqueza de especies a medida que se avanza hacia el Ecuador geográfico; el piedemonte de los departamentos del Caquetá y Putumayo fueron los de mayor riqueza de especies en la Cordillera Oriental y se atribuye a la confluencia de las biotas Andina y Amazónica; (2) para la vertiente occidental no se observó una tendencia clara de la riqueza específica con la latitud; (3) en la vertiente oriental se encontró un recambio de especies superior al $80 \%$ entre muestras distanciadas 250 a $300 \mathrm{~km}$ lineales, no obstante, se plantea qué problemas metodológicos generaron estos altos valores de recambio; (4) en la vertiente occidental se encontraron altos valores del recambio de especies entre sitios de robledales indicando que este tipo de vegetación no es homogénea en la composición de estas dos familias. Se establecen recomendaciones para el ordenamiento de áreas de conservación en la vertiente oriental de la Cordillera Oriental.

\begin{abstract}
Based on standardized inventories, species richness patterns of Rubiaceae and Melastomataceae were evaluated along latitudinal and altitudinal gradients of the Eastern Cordillera of the Andes of Colombia. The inventory represents 30 and $23 \%$ of the species of Melastomataceae and Rubiaceae known in Colombia respectively. Altitudinal trends found: (1) a decrease in richness with increasing altitude, this pattern being more striking for Rubiaceae than for Melastomataceae; (2) high values of species turnover along the elevational gradient, with a complete change in species composition between sites separated by an altitude of $1000 \mathrm{~m}$. Latitudinal trends found: (1) an increase in species richness with decreasing latitude on the eastern slope of the eastern Andes; the highest levels of species richness
\end{abstract}

Instituto de Investigación de Recursos Biológicos “Alexander von Humboldt”. Diagonal 27 No. 15-09, Bogotá D.C., Colombia. hummendoza@ gmail.com 
were found in the foothills in the departments of Caquetá and Putumayo, possibly due to the confluence of Andean and Amazon biota; (2) no clear trends of species richness on the western slopes; (3) a turnover of more than $80 \%$ of species between samples separated by $250-300 \mathrm{~km}$ on the eastern slope of the eastern Andes, however, these high values could be an artifact of methodological issues; (4) high values of species turnover between Oak-forest of the western slope, indicating that the species' composition of these two families is not homogeneous within this vegetation type (oakforest). Recommendations for establishing some conservation priorities within the eastern Andes of Colombia are given based on the results.

\section{INTRODUCCIÓN}

El comportamiento de la diversidad en diferentes escalas ha sido estudiado en gradientes enteros altitudinales y latitudinales (Kitayama, 1992; Kitayama \& Mueller-Dombois, 1994; Kappelle \& Zamora, 1995; Rahbek, 1995; Boyle, 1996; Lieberman et al., 1996; Vázquez \& Givinish, 1998; Kessler, 2000; Kessler et al., 2001; Koleff \& Gaston, 2001; Kessler, 2002, 2002a; Krömer et al., 2005; Cardelús et al., 2006; Kessler et al., 2011; Sanders \& Rahbek, 2012). En términos generales se conoce que la riqueza específica decrece con el incremento de la altitud, que es más común la presencia de un pico (hump-shaped) o franja intermedia con mayor riqueza que un decrecimiento lineal, y que no hay un solo mecanismo general que explique la variación altitudinal (Kessler et al., 2001; Nathan, 2002; Sanders \& Rahbek, 2012). Igualmente se conoce que las regiones tropicales es donde se concentra la mayor diversidad biológica del planeta y que esta decrece a medida que se avanza desde el Ecuador geográfico hacia los polos (Gaston et al., 1995).

No obstante, la mayor parte de los trabajos en gradientes altitudinales se han concentrado en las zonas templadas y enfocados a un solo grupo de organismos y muy pocos a la comparación entre grupos. Asimismo, son pocos los trabajos en gradientes latitudinales regionales en el neotrópico. Kessler (2000) realizó el único trabajo en el neotrópico en el que se ha analizado el comportamiento de la diversidad en el gradiente altitudinal comparativo de varias familias, incluyendo a Melastomataceae.

En Colombia los trabajos que han generado información en el gradiente altitudinal son escasos, la mayoría de ellos tienen un carácter cualitativo y se enfocan a la definición y en la descripción de comunidades fitosociológicas y de niveles taxonómicos (familias y géneros; Rangel et al., 1982; Rangel \& Lozano, 1986; Rangel, 1991; Wolf, 1993; Cleff et al., 2003; Wolf, 2003). En el gradiente latitudinal no existen trabajos hasta el momento.

La cordillera Oriental colombiana, en especial el flanco oriental, es un escenario excelente para determinar patrones de la riqueza específica en estos dos gradientes, puesto que aún conservan importantes remanentes de bosques andinos que confluye con las biotas de la Orinoquia y la Amazonia y valles secos interandinos.

Con el presente trabajo se buscó dilucidar patrones de la riqueza específica de plantas en los gradientes altitudinales y latitudinales de la cordillera Oriental que permitan generar pautas que puedan ser utilizadas en un futuro para direccionar planes de conservación en el norte de los Andes. Para esto se utilizaron como grupos indicadores a las familias Melastomataceae y Rubiaceae (Mendoza et al., 2004; Villareal et al., 2004).

Con el uso de estos dos grupos se pretendió determinar similitudes y diferencias en el comportamiento de la riqueza específica y recambio de especies a lo largo de gradientes en la cordillera Oriental. Estas dos familias comparten estrategias evolutivas, ya que son grupos muy diversificados en el neotrópico, también se encuentran en la mayoría de los ecosistemas, cubren rangos altitudinales amplios, son abundantes en bosques andinos y húmedos tropicales, presentan pocos géneros ampliamente diversificados y los restantes representados por pocas especies y tienen dos grandes grupos de géneros: los de frutos capsulares 
y otros con frutos carnosos. La mayor diferencia entre las dos familias radica en el tipo de flor y la oferta a los polinizadores (Mendoza et al., 2004; Mendoza \& Ramírez, 2006).

\section{ÁREA DE ESTUDIO}

El área de estudio se localiza en la cordillera de los Andes de Colombia, entre el extremo sur de la Serranía los Motilones al norte ( $9^{\circ} 10^{\prime}$ longitud N) y el río San Miguel al sur ( $0^{\circ} 20^{\prime}$ longitud N); entre los 1000 y $3500 \mathrm{~m}$ de altitud.

La cordillera de los Andes representa aproximadamente el 30\% de la extensión de Colombia y una vez ingresa a este país se ramifica en tres grandes cordilleras. El área estudiada cubre la vertiente oriental del denominado macizo colombiano (vertiente oriental de los Andes), y las vertientes oriental (cuencas de los ríos Orinoco y Amazonas), occidental (cuenca del río Magdalena) y la que drena hacia el río Zulia (que desemboca en el golfo de Maracaibo) de la Cordillera Oriental (Figura 1).

La cordillera oriental (CO) es el ramal más largo, ancho y con mayor altitud de las ramificaciones del norte de los Andes. Su longitud es de cerca de $1200 \mathrm{~km}$, en su parte más ancha alcanza los 200 $\mathrm{km}$ y presenta picos de hasta $4500 \mathrm{~m}$ de altitud. Su origen geológico se remonta al Eoceno inferior (50 $\mathrm{ma})$, pero con una fase definitiva de emergencia en el Mioceno (18 ma) y su configuración final en el Plioceno hace 7 a 5 ma (Van der Hammen, 1958; Van der Hammen et al., 1983; Flórez, 2004).

La CO presenta en el extremo norte una bifurcación que origina la cordillera de Mérida en Venezuela y la serranía de Perijá en Colombia, drenando parte de sus cuencas hacia el golfo de Maracaibo. $\mathrm{Su}$ orientación en Colombia abarca un gradiente latitudinal de aproximadamente $980 \mathrm{~km}$, lo que la constituye en un excelente escenario para determinar como influye este gradiente en la distribución de la biota.

Los muestreos se enfocaron principalmente en la vertiente oriental de esta cordillera (voCO), la cual drena hacia la Orinoquia y Amazonia, y se localizaron en la franja de vegetación denominada como selva Subandina, de acuerdo con Cuatrecasas (1958), o bosque Subandino, de acuerdo con Rangel \& Lozano (1986) y Van der Hammen \& Rangel (1997), entre los 1000 y 2000 m de altitud. Sin embargo, en algunas localidades se realizaron muestreos en la franja entre 2000 y $3100 \mathrm{~m}$ de altitud, que comprende las formaciones denominadas como Selvas Andinas o Bosque Andinos, Altoandinos y Páramos (Cuatrecasas, 1958; Rangel \& Lozano, 1986; Tabla 1).

Otros muestreos se realizaron sobre el flanco occidental de la $\mathrm{CO}$ y sobre la vertiente del río $\mathrm{Zu}-$ lia, que drena hacia el golfo de Maracaibo. En las localidades sobre la voCO, los bosque estudiados corresponden a lo que Lozano et al. (1996) denominan bosques mixtos, debido a la completa ausencia del roble. En los otros flancos, la totalidad de los muestreos se localizaron en bosque de roble (dominados por Quercus humboldtii o Colombolanus excelsa, Fagaceae).

Fisonómicamente, los bosques del área de estudio son similares a otros bosques andinos de Colombia, donde hay una gran cobertura de epífitas que se incrementa con la altitud. El sotobosque es denso, la altura máxima de los árboles oscila entre los 15 y $25 \mathrm{~m}$ y predominan lianas y hemiepífitas asociadas a árboles de troncos gruesos. Los bosques de roble se caracterizan por la alta densidad de epífitas que crecen sobre la hojarasca en el suelo, sotobosque despoblado y menor número de estratos arbóreos que los bosques mixtos.

Climáticamente hay variaciones dentro y entre los flancos de la CO. En la voCO la precipitación fluctúa entre los 2500 y $6000 \mathrm{~mm} / \mathrm{año}$; los lugares más húmedos se localizan en la zona de Villavicencio (cerca de los farallones de Medina), extremo suroccidental Meta y Putumayo, donde las precipitaciones alcanzan los 5000 a $6000 \mathrm{~mm} /$ año (IGAC, 2003). En el resto de la vertiente la precipitación oscila entre los 2500 y $3000 \mathrm{~mm} /$ año (IGAC, 2003). En las localidades sobre el flanco occidental y la vertiente del río Zulia la precipitación oscila entre los 2500-3000 mm/año (IGAC, 

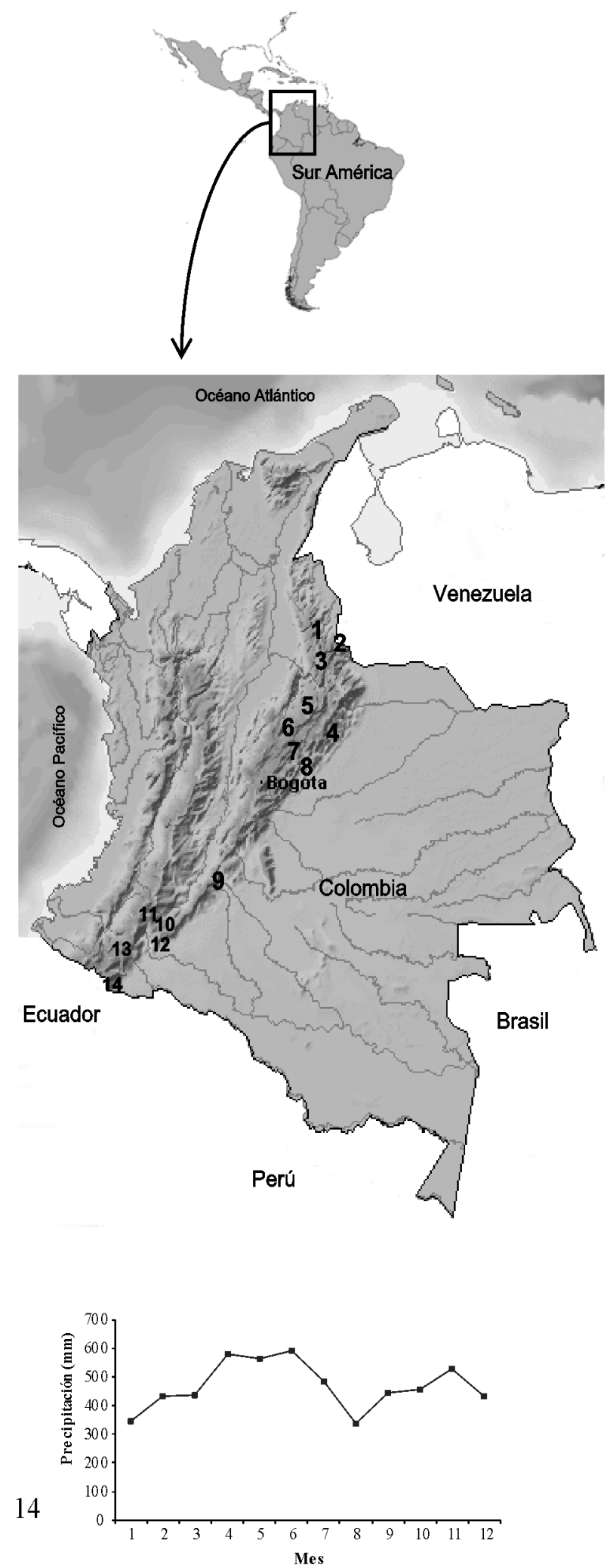

Estación de Churayaco, Pto Asis, Putumayo, 500m, período 1981-95

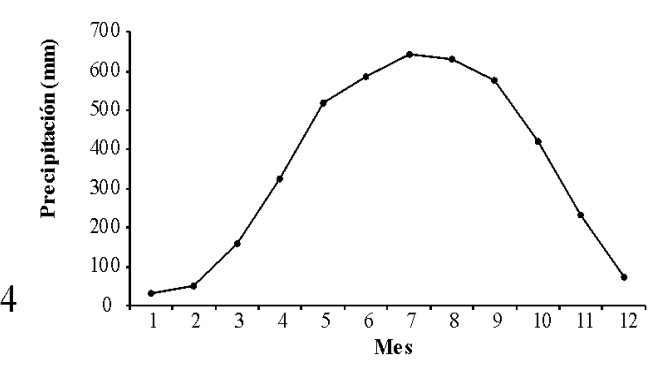

Estación de Pajarito, Boyacá, 842m, período 1970-96

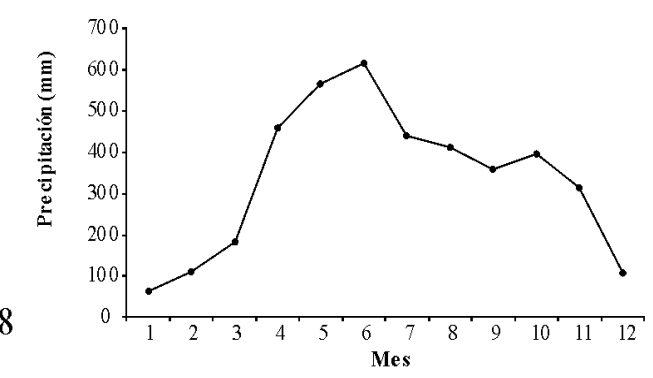

Estación de Medina, C/marca, 480m, período 1970-97

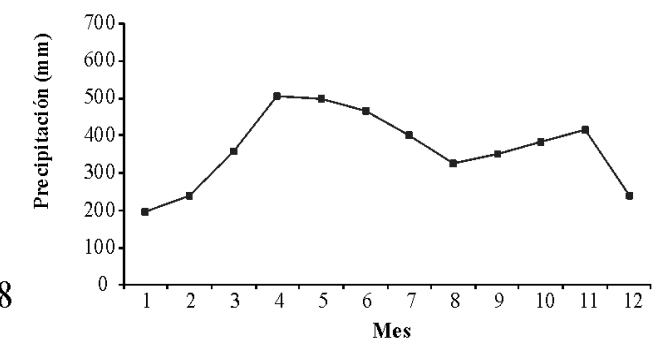

Estación de Medina, Cundinamarca, 320m, período 1972-95

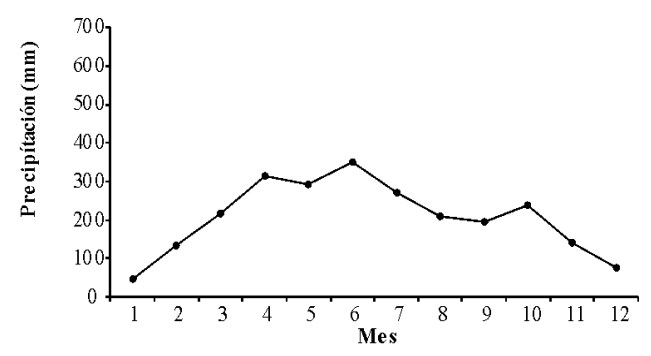

Estación de San Vicente delCaguán, San Vicente del Caguán, Caquetá, $300 \mathrm{~m}$, período $1970-92$

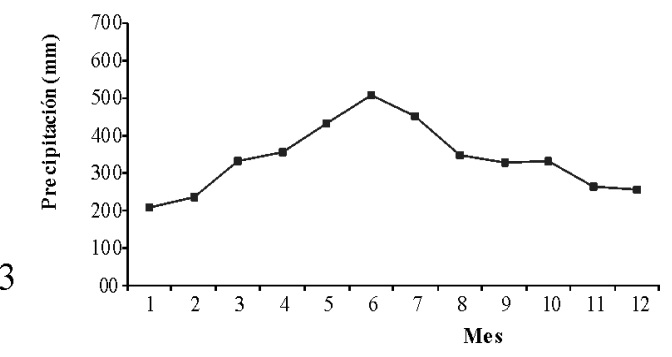

Estación de Mocoa, Mocoa, Putumayo, 579m, período 1959-79

Figura 1. Localización del área de estudio y puntos de muestreos. Los números corresponden a localidades enumeradas en la tabla 1 
2003). Altitudinalmente los máximos valores de la precipitación se encuentran entre los 1500-2200 $\mathrm{m}$, en la línea que corresponde a los denominados bosques nublados y hay un marcado decrecimiento de la precipitación con el incremento de la altitud (IGAC, 1982).

En toda el área de estudio los registros de precipitación indican un comportamiento bimodal, con un periodo máximo de lluvias entre los meses de marzo a abril y mayo a junio y otro menor entre los meses de octubre a noviembre (Figura 1). La clasificación climática del área de estudio se puede considerar templado húmedo a perhúmedo (1000$2200 \mathrm{~m}$ de altitud) y frío húmedo (1800-2200 a 3000-3200 m de altitud).

En la actualidad, los remanentes de bosque de la voCO representan el 53.2\% (ca. 2519000 ha) del área boscosa original en la $\mathrm{CO}$, y cerca del $30 \%$ de la cobertura de bosques remanentes de bosque Subandino, Andino y Altoandino de los Andes de Colombia (Armenteras et al., 2007). En su gran mayoría los sitios estudiados presentan una cobertura boscosa continua exceptuando localidades como la cuenca del río Cusiana, Parque Nacional Natural (PNN) Cueva de Los Guacharos y algunos sectores de la parte baja del PNN Tama, donde existe fragmentación de los bosques. Todos los sitios de muestreo se localizaron en las zonas donde se evidenció la menor intervención antrópica en caso de existir.

\section{MÉTODOS}

\section{TÉCNICA DE MUESTREO}

El trabajo de campo se realizó entre febrero de 1997 y marzo del 2002, principalmente en los periodos secos a principio de cada año; en total se muestrearon 35 puntos entre los 1000 y $3100 \mathrm{~m}$ de altitud en toda la CO (Tabla 1).

En cada punto de muestreo se realizaron inventarios exhaustivos de las especies de las familias de Melastomataceae y Rubiaceae utilizando el método propuesto por Mendoza et al. (2004) y Villareal et al. (2004). Este método consiste en censar todas las especies de estas dos familias en un área de 0.4 ha, donde se realizan diez transectos de $80 \times 5 \mathrm{~m}$, cada transecto se subdivide en 160 parcelas de 5 x $5 \mathrm{~m}$; se determina la presencia de todas las especies de Rubiaceae y Melastomataceae en cada parcela. Solamente se consideran datos de presenciaausencia de las especies y la frecuencia máxima de una especie es de 160, lo que representa una medida burda de la abundancia. La totalidad de los transectos en un punto de muestreo se localizó cerca y cubrió un área relativamente homogénea de aproximadamente cinco hectáreas.

En todos los puntos muestreados se herborizaron ejemplares de las especies censadas, los cuales se depositaron en el herbario FMB del Instituto Alexander von Humboldt. Para la identificación de las especies se utilizaron claves (e.i. Steyermark, 1974; Wurdack, 1973, 1980; Andersson, 1993; Andersson \& Taylor, 1994; Berry et al., 2001; Mendoza et al., 2004; Mendoza \& Ramírez, 2006), se revisaron las colecciones de los herbarios COL, FMB en Colombia y MO en Estados Unidos. En las Rubiaceae se contó con la colaboración de Charlotte Taylor de Missouri Botanical Garden.

\section{DISEÑO DE MUESTREO}

En seis localidades a lo largo de la voCO (PNN Tama, cuenca río Cusiana, farallones de Medina, PNN cordillera Los Picachos, PNN Indiwasi, El Mirador-río Rumiyaco) se realizaron muestreos alrededor de tres puntos altitudinales: 1000, 1500 y $2000 \mathrm{~m}$ de altitud. Con este conjunto de datos se analizó la variación latitudinal de la riqueza y recambio de especies.

En la parte norte del área de estudio se realizaron inventarios y se cubrió un gradiente entre los 1000 y 3000 m: en el PNN Tama con muestreos cada 300-450 m altitudinales, y en Sisavita entre los 2000 y $3100 \mathrm{~m}$ con muestreos cada 200$300 \mathrm{~m}$. Con este conjunto de datos se analizó el comportamiento de la riqueza de especies en el gradiente altitudinal. No se incluyeron inventarios en zonas por debajo de los $1000 \mathrm{~m}$ de altitud ya que la vegetación en esta franja se encuentra 
Tabla 1. Localidades muestreadas en la Cordillera Oriental, Colombia, norte de los Andes

\begin{tabular}{|c|c|c|c|c|c|}
\hline \multicolumn{2}{|c|}{$\begin{array}{l}\text { Localidad y estaciones de muestreo } \\
\text { Altitud msnm }\end{array}$} & \multirow{2}{*}{$\begin{array}{c}\text { Departamento } \\
\text { Norte de } \\
\text { Santander }\end{array}$} & \multirow{2}{*}{$\begin{array}{c}\text { Subcuenca / Cuenca } \\
\begin{array}{c}\text { Vertiente río Zulia -Golfo } \\
\text { de Maracaibo }\end{array}\end{array}$} & \multirow{2}{*}{$\begin{array}{c}\text { Coordenadas generales } \\
7^{0} 26^{\prime} 51^{\prime \prime} \mathrm{N} / 72^{\circ} 51^{\prime} 8^{\prime \prime} \mathrm{W} \\
-7^{0} 27^{\prime} 57^{\prime} 53^{\prime \prime} \\
\mathrm{N} / 72^{0} 50^{\prime} 58^{\prime} 46^{\prime \prime} \mathrm{W}\end{array}$} & \multirow{2}{*}{$\begin{array}{l}\text { Tipos de formación vegetal y estado de } \\
\text { conservación }\end{array}$} \\
\hline 1 & $\begin{array}{l}\text { Sisavita - Nudo de Santurban ( } 6 \text { muestreos) } \\
2050 \text { (Robledal) } \\
2000 \\
2300 \\
2500 \\
2800 \\
3100\end{array}$ & & & & \\
\hline 3 & $\begin{array}{l}\text { El Rasgón ( } 1 \text { muestreo) } \\
2300 \text { (Robledal) }\end{array}$ & Santander & $\begin{array}{l}\text { Vertiente occidental, ríos } \\
\text { De Oro-Magdalena }\end{array}$ & $7^{0} 2^{\prime} \mathrm{N} / 72^{0} 57^{\prime} \mathrm{W}$ & $\begin{array}{l}\text { Andino; bosque de } Q . \text { humboldtii. } \\
\text { Intervención antrópica no evidente }\end{array}$ \\
\hline 5 & $\begin{array}{l}\text { Reserva Natural Cachalú ( } 1 \text { muestreo) } \\
2000 \text { (Robledal) }\end{array}$ & Santander & $\begin{array}{l}\text { Vertiente occidental, ríos } \\
\text { Fonce-Magdalena }\end{array}$ & $6^{0} 9^{\prime} 54^{\prime \prime} \mathrm{N} / 73^{\circ} 8^{\prime} 15^{\prime \prime} \mathrm{W}$ & $\begin{array}{l}\text { Andino; bosque de } Q . \text { humboldtii. } \\
\text { Intervención antrópica no evidente }\end{array}$ \\
\hline 6 & $\begin{array}{l}\text { Virolín (Reserva Natural Guanentá-Alto río Fonce) } \\
(1 \text { muestreo) } \\
1750 \text { (Robledal) }\end{array}$ & Santander & $\begin{array}{l}\text { Vertiente occidental, ríos } \\
\text { Fonce-Magdalena }\end{array}$ & $6^{0} 6^{\prime} 19^{\prime \prime} \mathrm{N} / 73^{0} 13^{\prime} 20^{\prime \prime} \mathrm{W}$ & $\begin{array}{l}\text { Subandino; bosque de Colombobalamus } \\
\text { excelsa. bosque intervenido pero con un } \\
\text { adelantado proceso de regeneración. }\end{array}$ \\
\hline $6^{\mathrm{a}}$ & $\begin{array}{l}\text { Serranía Los Yariguies } \\
1800 \text { Cerro Las Tetas (Robledal) } \\
2150 \text { San Cayetano (Robledal) }\end{array}$ & Santander & $\begin{array}{l}\text { Vertiente occidental, río } \\
\text { Magdalena }\end{array}$ & & 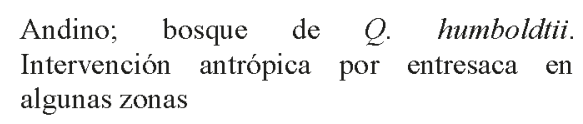 \\
\hline 7 & $\begin{array}{l}\text { Cañón del río Pómeca ( } 1 \text { muestreo) } \\
2100 \text { (Robedal) }\end{array}$ & Boyacá & $\begin{array}{l}\text { Vertiente occidental, ríos } \\
\text { Chicamocha-Magdalena }\end{array}$ & $\begin{array}{c}5^{0} 48^{\prime} 80^{\prime \prime} \mathrm{N} / 73^{\circ} 28^{\prime} 97^{\prime \prime} \\
\mathrm{W}\end{array}$ & $\begin{array}{l}\text { Andino; bosque de } Q . \quad \text { humboldtii. } \\
\text { Intervención antrópica por pastoreo y } \\
\text { extracción de leña en algunas zonas. }\end{array}$ \\
\hline 10 & $\begin{array}{l}\text { Parque Nacional Natural Cueva de Los Guacharos } \\
\text { (1 muestreo) } \\
1800 \text { (Robledal) }\end{array}$ & Huila & $\begin{array}{l}\text { Vertiente occidental, ríos } \\
\text { Zuaza-Magdalena }\end{array}$ & $\begin{array}{c}1^{0} 36^{\prime} 59^{\prime \prime} \mathrm{N} / 76^{\circ} 6^{\prime} 15.7^{\prime \prime} \\
\mathrm{W} 1^{0} 37^{\prime} 21^{\prime} 4^{\prime \prime} \\
\mathrm{N} / 76^{\circ} 6^{\prime} 16.3^{\prime \prime} \mathrm{W}\end{array}$ & $\begin{array}{l}\text { Andino; bosque de } C \text {. excelsa. Bosque } \\
\text { intervenido hace más de cuarenta años; en } \\
\text { avanzado estado de regeneración. }\end{array}$ \\
\hline 11 & $\begin{array}{l}\text { Reserva Natural Yalcones (1 muestreo) } \\
2400 \text { (Robledal) }\end{array}$ & Huila & $\begin{array}{l}\text { Vertiente occidental, río } \\
\text { Magdalena }\end{array}$ & $\begin{array}{c}1^{0} 48^{\prime} 36^{\prime \prime} \mathrm{N} / 76^{\circ} 20^{\prime} 59^{\prime \prime} \\
\mathrm{W}\end{array}$ & $\begin{array}{l}\text { Andino; bosque de } Q . \text { humboldtii. } \\
\text { Intervención antrópica por tala selectiva pero } \\
\text { no reciente. }\end{array}$ \\
\hline 11 & $\begin{array}{l}\text { Palestina -San Agustin (4 muestreos) } \\
\text { El Caracol } 2120 \text { (Robledal) } \\
\text { Jericó } 1980 \text { (Robledal) } \\
\text { La Guajira } 1970 \text { (Robledal) } \\
\text { Villa Fátima } 1950 \text { (Robledal) }\end{array}$ & Huila & $\begin{array}{l}\text { Vertiente occidental, río } \\
\text { Magdalena }\end{array}$ & $\begin{array}{c}1^{\circ} 39^{\prime} 54^{\prime \prime} \mathrm{N} / 76^{\circ} 08^{\prime} 28^{\prime \prime} \\
\mathrm{W} \\
1^{\circ} 48^{\prime} 45^{\prime \prime} \mathrm{N} / 76^{\circ} 20^{\prime} 29^{\prime \prime} \\
\mathrm{W}\end{array}$ & $\begin{array}{l}\text { Andino; bosque de } Q \text {. humboldtii (El Caracol } \\
\text { y Villa Fátima) y C. excelsa (Jericó y La } \\
\text { Guajira). Intervención antrópica por tala } \\
\text { selectiva reciente. }\end{array}$ \\
\hline
\end{tabular}


Localidad y estaciones de muestreo

Altitud msnm

2 Parque Nacional Natural Tama (5 muestreos)

1000

1450

2400

2700

3000

4 Cuenca Rio Cusiana (2 muestreos)

1200

2000

8 Serranía Farallones de Medina (3 muestreos)

1000

1500

2000

9 Parque Naciona Natural Cordillera Los Picachos (2 muestreos)

1600

2000

12 Río Yurayaco - PNN Indiwasi (2 muestreos)

1000

1450

13 EI Mirador (1 muestreo)

2000

14 Cuenca baja río Rumiyaco-Territorio Kofán (2

muestreos)

1000

1450

Departamento

Subcuenca / Cuenca

Coordenadas generales

Tipos de formación vegetal y estado de

conservación

Santander Vertiente Oriental, río
Arauca-Orinoco

Boyacá

Cundinamarca

Vertiente oriental, rios Meta-Orinoco

Caquetá

\section{Vertiente oriental, ríos} Guaviare-Orinoco

Caquetá

Nariño

Vertiente Oriental, río Arauca-Orinoco

Vertiente oriental, ríos Caquetá-Amazonas
$5^{0} 26^{\prime} 05^{\prime \prime} \mathrm{N} / 72^{\circ} 41^{\prime} 30^{\prime \prime} \mathrm{W}$
$5^{\circ} 23^{\prime} 39^{\prime \prime} \mathrm{N} / 72^{\circ} 42^{\prime} 17^{\prime \prime} \mathrm{W}$ Intervención antrópica evidente pero en puntos localizados. Los muestreos evadieron zonas evidentemente intervenidas.

$5^{0} 35^{\prime} 10^{\prime \prime} \mathrm{N} / 73^{0} 25^{\prime} 33^{\prime \prime} \mathrm{W}$ Subandino-Andino, bosques mixtos. No hay evidencias de intervención antrópica excepto a los $100 \mathrm{~m}$ en donde se encuentra un bosque posiblemente en donde se realizó leñateo en el pasado.

$2^{0} 47^{\prime} 51^{\prime \prime N} / 74^{0} 51^{\prime} 18^{\prime \prime} \mathrm{W}$ Subandino-Andino, bosques mixtos. Se evidenciaron procesos de intervención en el pasado a los $1600 \mathrm{~m}$, sin embargo el bosque se encuentra en una avanzada etapa de regeneración.

${ }^{0} 20^{\prime} 55^{\prime \prime} \mathrm{N} / 76^{\circ} 6^{\prime} 11^{\prime \prime} \mathrm{W}$ Subandino-Andino, bosques mixtos. No se evidencio intervención en los puntos muestreados.

$01^{\circ} 04^{\prime} 21^{\prime \prime N} / 76^{\circ} 44^{\prime} 04^{\prime \prime}$ Andino, bosque mixto. No se observó W intervención, sin embargo debieron ser afectados en la década de 1930.

$00^{\circ} 28^{\prime} 47^{\prime \prime N} / 77^{\circ} 17^{\prime} 45^{\prime \prime}$ Subandino-Andino, bosques mixtos. No se W observo procesos de intervención de la vegetación. Sí hay caza 
fuertemente transformada y son muy pocos y pequeños los relictos boscosos.

En el flanco occidental de la CO se realizaron cinco muestreos en bosques de Robledales de Quercus humboldtii o Colombobalanus excelsa (Fagaceae). A este conjunto de datos se sumó un muestreo a los 2050 m en Sisavita (Norte de Santander) en un bosque dominado por $Q$. humboldtii.

\section{ANÁLISIS DE DATOS}

Se realizaron curvas de acumulación de especies por punto de muestreo. Se utilizó el programa EstimateS 7.5 (Collwell, 2005) y se emplearon modelos de curvas de acumulación como MMMean (sigla del modelo de MichaelisMenten que describe una curva de acumulación); y estimadores no parametricos como Chao2 e ICE para determinar el número de especies esperadas. Chao2 (nombre proveniente del autor Anne Chao) e ICE (Incidence-based Coverage Estimator) son modelos de curvas de acumulación que se basan en datos de incidencia (presencia ausencia) y consideran el número de especies con frecuencia 1 y 2 . Con estos valores se calculó la representatividad de los muestreos, definida como la relación expresada en porcentaje entre los valores observados (número de especies en 0.4 ha) y esperados del número de especies.

Se determinó el comportamiento de la riqueza específica, recambio de especies y riqueza regional en toda el área de estudio. Como riqueza regional se definió el número total de especies considerando todos los muestreos en la CO. Este valor se comparó con el total de especies registradas hasta el momento para el país de las familias Rubiaceae y Melastomataceae.

El recambio de especies se estableció al comparar la composición de dos puntos muestreados, y se estimó utilizando el Índice de Complementariedad (IC; Ec. 1) propuesto por Colwell \& Coddington (1994), el cual se define como:
$\mathrm{IC}=(\mathrm{A}+\mathrm{B}-2 \mathrm{C}) /(\mathrm{A}+\mathrm{B}-\mathrm{C})$

Ec. 1

Donde

$A=$ No. de especies muestra $A$

$B=$ No. de especies muestra $B$

$\mathrm{C}=$ número de especies compartidas entre muestras

El IC varía entre 0 y 1 o 100 si se expresa en porcentaje. Cuando dos muestras tienen un IC igual a 1 o 100, indica que no tienen especies compartidas por lo que se complementan en su totalidad. Se calculó el valor porcentual del IC entre todos los puntos muestreados en la $\mathrm{CO}$; luego se tabularon los datos y se determinó el rango de variación el IC entre franjas altitudinales distanciadas por 250 y $500 \mathrm{~m}$ altitudinales. Para determinar cómo es el recambio de especies en el gradiente latitudinal, se determinó la distancia entre las localidades estudiadas y se hallo el rango en el cual varía el IC en tres franjas altitudinales: 900-1200 m, 1400-1600 m y 1800-2100 m.

La riqueza específica se definió como el número de especies de cada familia por punto de muestreo (densidad de especies). Se analizó el comportamiento de este nivel de diversidad en los gradientes altitudinal y latitudinal utilizando el valor promedio de la riqueza de los transectos de 80 x $5 \mathrm{~m}(\mathrm{n}=10)$ y se obtuvo su respectivo intervalo de confianza. Para el gradiente altitudinal se utilizaron de forma independiente los siguientes conjuntos de datos: Sisavita (Norte de Santander). Gradiente entre los 2000 y 3100 m de altitud con muestreos cada $250-300 \mathrm{~m}$ altitudinales ( 5 puntos de muestreo) y Tama. Gradiente entre los 900 y $3000 \mathrm{~m}$ de altitud, con muestreos cada 300-450 m altitudinales (cinco puntos de muestreo).

Para el análisis del comportamiento latitudinal se analizaron de forma independiente los siguientes conjuntos de datos: muestras en la voCO entre los 1000 y $2000 \mathrm{~m}$ de altitud distribuidas desde la frontera con Venezuela (PNN Tama) hasta la frontera con Ecuador (Territorio Kofán, Putumayo; 16 puntos de muestreo) y muestras en la vertiente occidental de la $\mathrm{CO}$ y del río Zulia en 
sitios de robledal (siete muestreos entre los 1750 y $2400 \mathrm{~m}$ de altitud).

\section{RESULTADOS}

\section{REPRESENTATIVIDAD}

Los inventarios locales presentaron una representatividad entre el 55 y $100 \%$ para las dos familias y solo en dos de los 35 puntos de muestreo se encontraron valores menores del $70 \%$ de las especies esperadas con el estimador Chao2 (Tabla 2). En la mayoría de los puntos de muestreo se obtuvieron curvas de acumulación asintóticas y siempre se encontraron especies raras con frecuencia de aparición de 1 o 2 (Uniques y Duplicates; Figura 2).

\section{RIQUEZA REGIONAL}

En toda el área de estudio se documentan en este trabajo 513 morfoespecies de las dos familias y se consideran colecciones generales adicionales; con los muestreos estandarizados se censaron el $78 \%$ de la totalidad de morfoespecies (Tabla 3, Anexo 1). El 74\% de los taxones colectados en parcelas se determinaron hasta especie y el $98 \%$ hasta género.

\section{VARIACIÓN DE LA RIQUEZA ESPECÍFICA EN EL GRADIENTE ALTITUDINAL}

En las localidades al norte del área de estudio (PNN Tama y Sisavita, Norte de Santander) se encontró que la riqueza de las dos familias tienen diferente comportamiento: por un lado, Rubiaceae presentó un evidente decrecimiento de la riqueza con el incremento de la altitud, siendo los sitios por encima de los $2500 \mathrm{~m}$ significativamente menos ricos que los de altitudes inferiores; por otro lado, Melastomataceae no presentó un decrecimiento y solo hubo una disminución significativa de la riqueza en localidades por encima de los 2800 $3000 \mathrm{~m}$ de altitud, es decir, en zonas de subpáramo y páramo (Figura 3).

\section{VARIACIÓN DE LA RIQUEZA ESPECÍFICA EN EL GRADIENTE LATITUDINAL}

En la voCO, las dos familias tienden a tener mayor número de especies por unidad de área en las localidades al sur del área de estudio (departamentos de Caquetá y Putumayo; Figura 4). Esto indica que la riqueza de especies aumenta hacia el Ecuador geográfico y alcanza un incremento entre el 1.9 y 2.9 niveles de magnitud entre los dos extremos del gradiente latitudinal. Este incremento de la riqueza presentó magnitudes muy similares entre las franjas altitudinales alrededor de $\operatorname{los} 1000 \mathrm{y}$ $1500 \mathrm{~m}$ (Figura 4).

El piedemonte del río Yurayaco (sur del departamento del Caquetá) y el territorio Kofán (límite de los departamentos de Putumayo y Nariño) fueron las zonas más ricas del área estudiada, mientras que Farallones de Medina(Cundinamarca) fue uno de los sectores con menor riqueza.

Por otra parte, la riqueza por unidad de área no mostró una tendencia clara en el gradiente latitudinal en las localidades sobre la vertiente occidental y del río Zulia de la CO (Figura 5). La totalidad de estas localidades se encuentran entre los 1800 y $2400 \mathrm{~m}$ de altitud y se caracterizan por presentar bosque dominados por Quercus humboldtii o Colombobalanus excelsa. La tendencia para las dos familias fue bastante similar y solo se observaron diferencias notables para la Reserva Natural Cachalú (Santander), donde la familia Rubiaceae fue más rica en especies que en el resto de localidades.

\section{RECAMBIO DE ESPECIES EN EL GRADIENTE ALTITUDINAL}

En franjas distanciadas por $500 \mathrm{~m}$ altitudinales en la voCO, el Índice de Complementariedad fluctuó ampliamente entre 52 y $95 \%$, no obstante, a medida que aumenta la distancia el IC aumentó y el rango de variación disminuyó (Tabla 4). En los farallones de Medina (Cundinamarca) fue donde se presentaron los valores más altos de recambio de especies en este gradiente. 
Tabla 2. Valores observados y esperados de la riqueza de especies y de representatividad de los muestreos de Melastomataceae y Rubiaceae en la CO. Chao2, ICE y MMMean son estimadores de la riqueza esperada de acuerdo a los muestreos estandarizados en 0.4 ha

\begin{tabular}{|c|c|c|c|c|c|c|c|c|c|c|}
\hline \multirow{2}{*}{$\begin{array}{l}\text { Localidad } \\
\text { Altitud msnm }\end{array}$} & \multicolumn{5}{|c|}{ Rubiaceae } & \multicolumn{5}{|c|}{ Melastomataceae } \\
\hline & Observado & Chao2 & ICE & MMMean & Representatividad \% & Observado & Chao2 & ICE & MMMean & Representatividad \% \\
\hline \multicolumn{11}{|l|}{ Sisavita } \\
\hline 2050 (Robledal) & 18 & 23 & 21 & 17 & $78-100$ & 13 & 13 & 13 & 13 & 100 \\
\hline 2000 & 21 & 21 & 21 & 22 & $95-100$ & 12 & 12 & 12 & 12 & 100 \\
\hline 2300 & 21 & 22 & 22 & 20 & $95-100$ & 13 & 12 & 12 & 12 & 100 \\
\hline 2500 & 18 & 21 & 20 & 17 & $86-100$ & 11 & 11 & 11 & 11 & 100 \\
\hline 2800 & 8 & 10 & 11 & 7 & $73-100$ & 10 & 10 & 10 & 10 & 100 \\
\hline 3100 & 3 & 3 & 3 & 2 & 100 & 5 & 5 & 5 & 4 & 100 \\
\hline \multicolumn{11}{|l|}{ El Rasgón } \\
\hline 2300 (Robledal) & 15 & 15 & 15 & 15 & 100 & 18 & 18 & 18 & 18 & 100 \\
\hline \multicolumn{11}{|l|}{ RN Cachalú } \\
\hline 2000 (Robledal) & 30 & 30 & 30 & 31 & $97-100$ & 22 & 22 & 22 & 23 & $96-100$ \\
\hline \multicolumn{11}{|c|}{ PNN Guanentá-Alto río Fonse } \\
\hline 1750 (Robledal) & 22 & 25 & 23 & 22 & $88-100$ & 23 & 31 & 27 & 21 & $74-100$ \\
\hline \multicolumn{11}{|c|}{ Serranía Los Yariguies } \\
\hline 1800 (Robledal) & 18 & 23 & 25 & 18 & $72-100$ & 14 & 14 & 14 & 14 & 100 \\
\hline 2150 (Robledal) & 12 & 12 & 12 & 13 & $92-100$ & 17 & 23 & 20 & 17 & $74-100$ \\
\hline \multicolumn{11}{|c|}{ Cañón del río Pomeca } \\
\hline 2100 & 19 & 20 & 20 & 21 & $90-95$ & 18 & 22 & 19 & 19 & $82-95$ \\
\hline \multicolumn{11}{|c|}{ PNN Cueva de Los Guacharos } \\
\hline 1800 (Robledal) & 15 & 15 & 16 & 15 & $94-100$ & 15 & 16 & 16 & 16 & 94 \\
\hline \multicolumn{11}{|l|}{ RN Yalcones } \\
\hline 2400 (Robledal) & 21 & 23 & 22 & 21 & $91-100$ & 21 & 21 & 21 & 22 & $95-100$ \\
\hline \multicolumn{11}{|c|}{ Palestina - San Agustín } \\
\hline 2120 (Robledal) & 14 & 14 & 14 & 15 & $96-100$ & 12 & 12 & 12 & 12 & $96-100$ \\
\hline 1980 (Robledal) & 15 & 15 & 15 & 16 & $93-100$ & 14 & 19 & 19 & 13 & $75-100$ \\
\hline 1970 (Robledal) & 16 & 16 & 16 & 17 & $96-100$ & 22 & 22 & 22 & 23 & $95-99$ \\
\hline 1950 (Robledal) & 11 & 11 & 11 & 11 & $96-100$ & 14 & 15 & 14 & 15 & $96-97$ \\
\hline \multicolumn{11}{|l|}{ PNN Tama } \\
\hline 1000 & 22 & 23 & 24 & 23 & $92-96$ & 22 & 23 & 23 & 22 & $96-100$ \\
\hline 1450 & 22 & 27 & 27 & 22 & $81-100$ & 17 & 18 & 18 & 17 & $94-100$ \\
\hline
\end{tabular}




\begin{tabular}{|c|c|c|c|c|c|c|c|c|c|c|}
\hline \multirow{2}{*}{$\begin{array}{l}\text { Localidad } \\
\text { Altitud msnm }\end{array}$} & \multicolumn{5}{|c|}{ Rubiaceae } & \multicolumn{5}{|c|}{ Melastomataceae } \\
\hline & Observado & Chao2 & ICE & MMMean & Representatividad \% & Observado & Chao2 & ICE & MMMean & Representatividad \% \\
\hline 2400 & 7 & 7 & 7 & 6 & 100 & 14 & 14 & 14 & 14 & 100 \\
\hline 2700 & 11 & 20 & 14 & 11 & $55-100$ & 19 & 27 & 22 & 19 & $70-100$ \\
\hline 3000 & 4 & 4 & 4 & 3 & 100 & 10 & 11 & 13 & 9 & $77-100$ \\
\hline \multicolumn{11}{|l|}{ Cusiana } \\
\hline 1200 & 16 & 20 & 20 & 20 & 80 & 9 & 9 & 11 & 11 & $82-100$ \\
\hline 2000 & 15 & 21 & 20 & 16 & $71-94$ & 9 & 9 & 9 & 10 & $90-100$ \\
\hline \multicolumn{11}{|c|}{ Farallones de Medina } \\
\hline 1000 & 15 & 17 & 18 & 18 & $83-88$ & 10 & 10 & 10 & 11 & $91-100$ \\
\hline 1500 & 17 & 20 & 23 & 19 & $74-89$ & 10 & 18 & 13 & 11 & $56-91$ \\
\hline 2000 & 11 & 11 & 11 & 12 & $92-100$ & 13 & 13 & 14 & 15 & $87-100$ \\
\hline \multicolumn{11}{|c|}{ PNN Serranía Los Picachos } \\
\hline 1600 & 16 & 21 & 20 & 16 & $76-100$ & 24 & 25 & 25 & 24 & $96-100$ \\
\hline 2000 & 9 & 10 & 11 & 9 & $82-100$ & 18 & 18 & 18 & 18 & 100 \\
\hline \multicolumn{11}{|l|}{ PNN Indiwasi } \\
\hline 1000 & 33 & 34 & 34 & 35 & $94-97$ & 29 & 31 & 32 & 29 & $91-100$ \\
\hline 1450 & 35 & 41 & 47 & 33 & $85-100$ & 37 & 39 & 40 & 36 & $93-100$ \\
\hline \multicolumn{11}{|l|}{ El Mirador } \\
\hline 2000 & 24 & 27 & 26 & 24 & $89-100$ & 26 & 30 & 30 & 26 & $87-100$ \\
\hline \multicolumn{11}{|c|}{ Territorio Kofán } \\
\hline 1000 & 35 & 38 & 36 & 36 & $92-97$ & 34 & 36 & 38 & 32 & $89-100$ \\
\hline 1450 & 34 & 39 & 38 & 33 & $87-100$ & 28 & 30 & 31 & 28 & $90-100$ \\
\hline
\end{tabular}


Tabla 3. Cifras generales del número de especies de Melastomataceae y Rubiaceae colectadas en la CO y comparación con los valores nacionales. * colectadas tanto en parcelas como en recorridos; ** Mendoza \& Ramírez (2005); *** Mendoza et al. (2004)

\begin{tabular}{cccc}
\hline Familia & $\begin{array}{c}\text { Número de especies totales } \\
\text { colectadas* }\end{array}$ & $\begin{array}{c}\text { Número de especies } \\
\text { colectadas en parcelas }\end{array}$ & $\begin{array}{c}\text { Número de especies } \\
\text { registradas en Colombia }\end{array}$ \\
\hline $\begin{array}{c}\text { Melastomataceae } \\
\text { Rubiaceae }\end{array}$ & 282 & 222 & ca. $950^{* *}$ \\
\hline
\end{tabular}
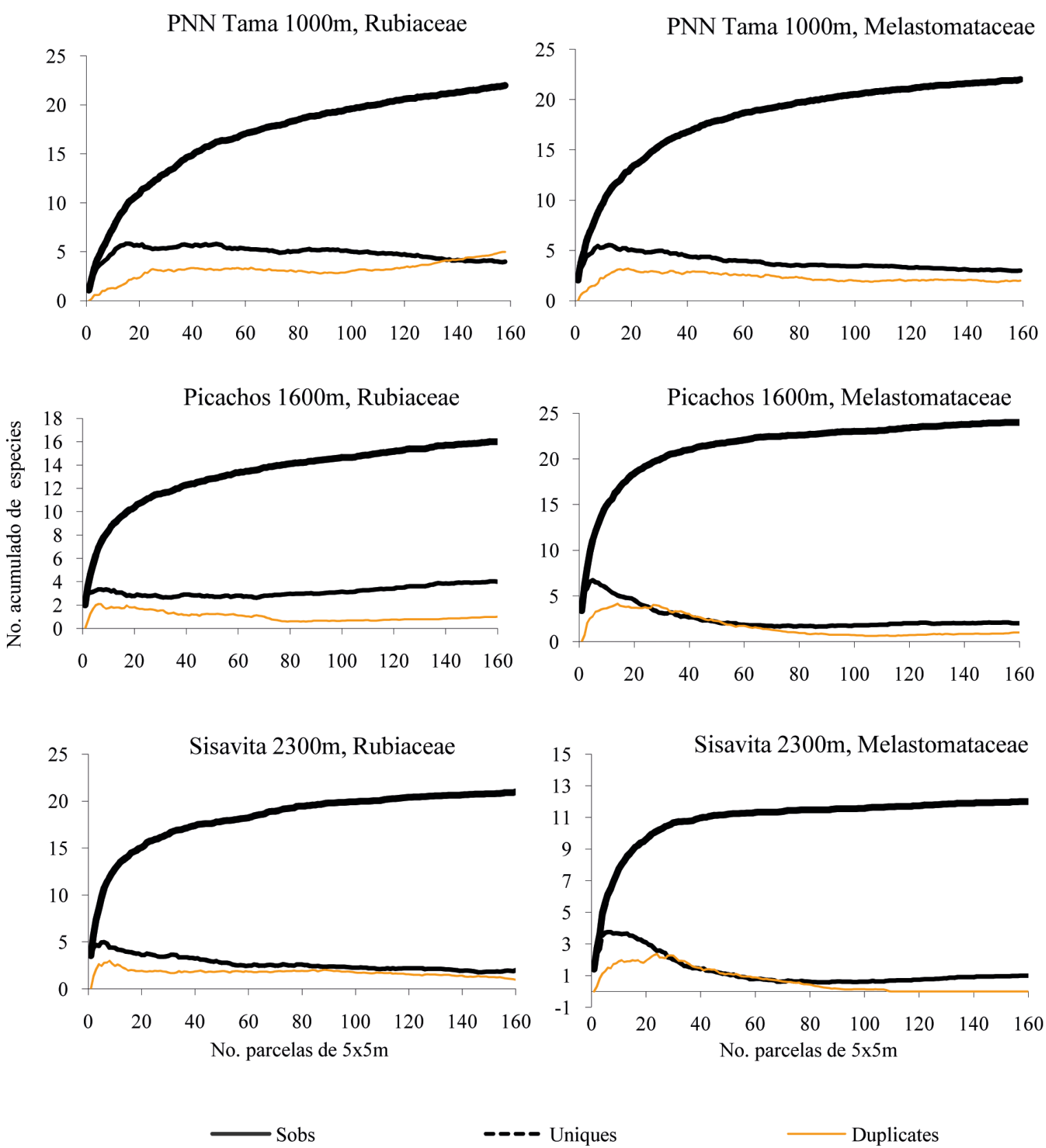

$$
\text { - - - Uniques }
$$

Duplicates

Figura 2. Curvas de acumulación de especies de Melastomataceae y Rubiaceae representativas de diferentes localidades en la CO. Sobs, curva de los valores observados; Uniques, curva de las especies registradas sólo en una muestra (frecuencia 1); Duplicates, curva de las especies registradas en dos muestras (frecuencia 2) 

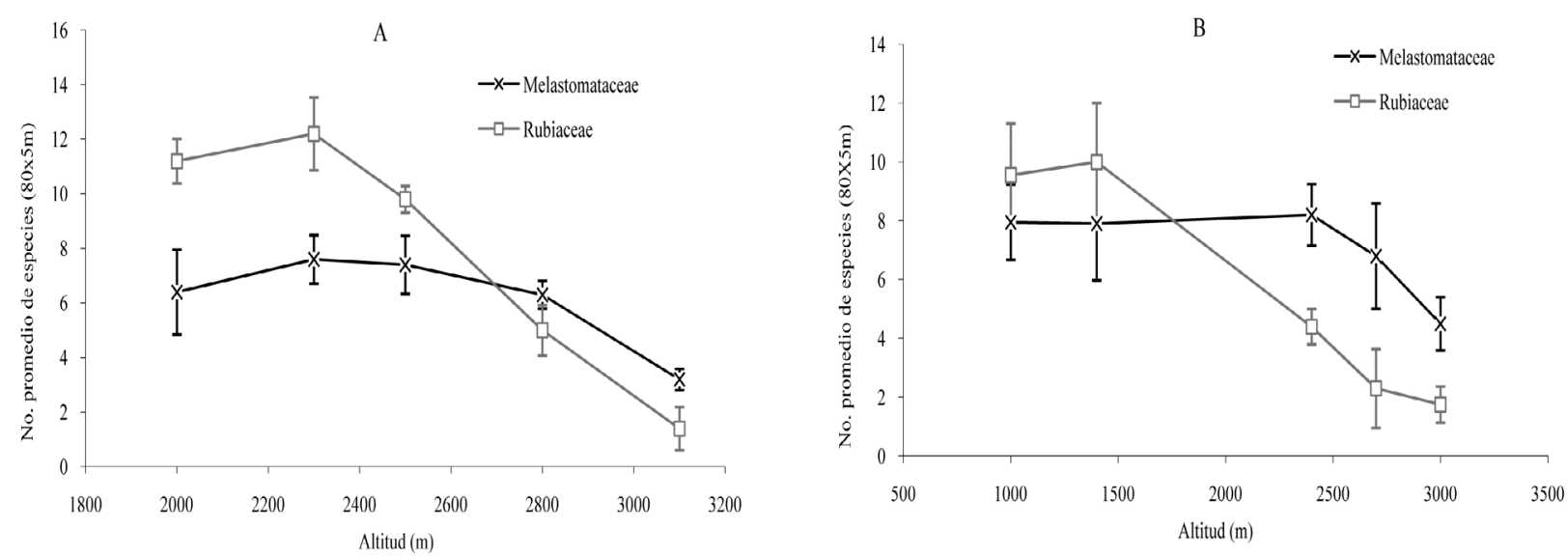

Figura 3. Comportamiento de la densidad de especies de Melastomataceae y Rubiaceae en el gradiente altitudinal en las al norte de la CO. La riqueza corresponde al promedio de submuestras (transectos de 80 x $5 \mathrm{~m}$ ); A) Sisavita, gradiente entre los 2000 y $3100 \mathrm{~m}$ de altitud con muestreos cada $250 \mathrm{~m}$ altitudinales; B) PNN Tama, gradiente entre los 1000 y $3000 \mathrm{~m}$ de altitud con muestreos cada $500 \mathrm{~m}$ altitudinales

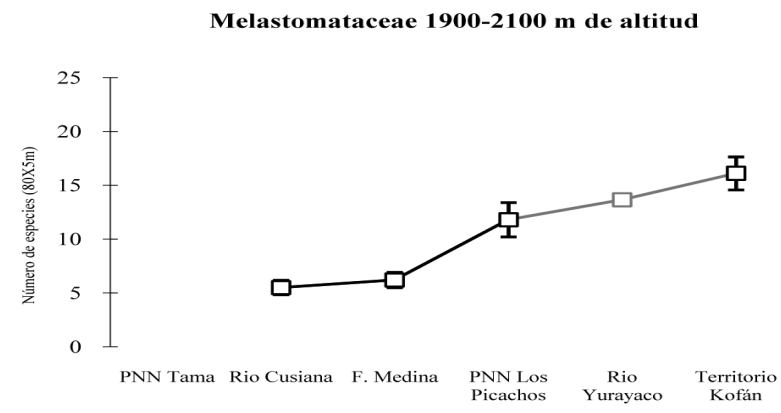

Melastomataceae 1400-1600 m de altitud

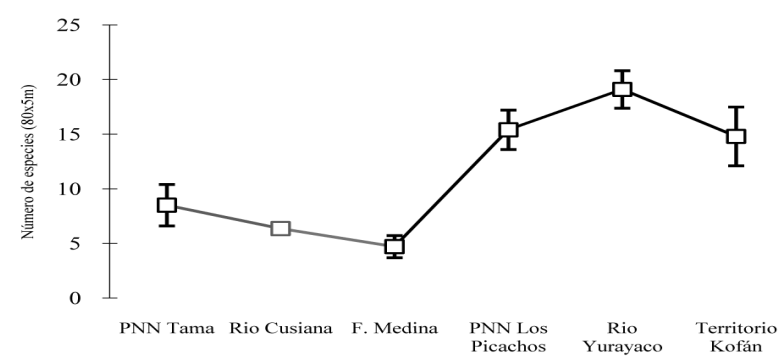

Melastomataceae 900-1200 m de altitud

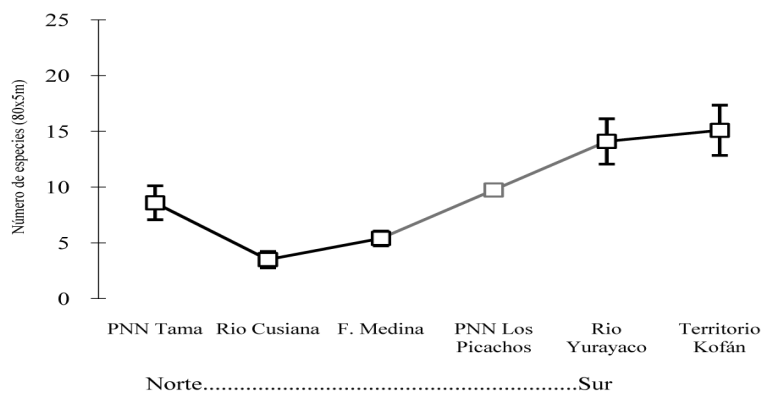

Rubiaceae Franja 1900-2100 m de altitud

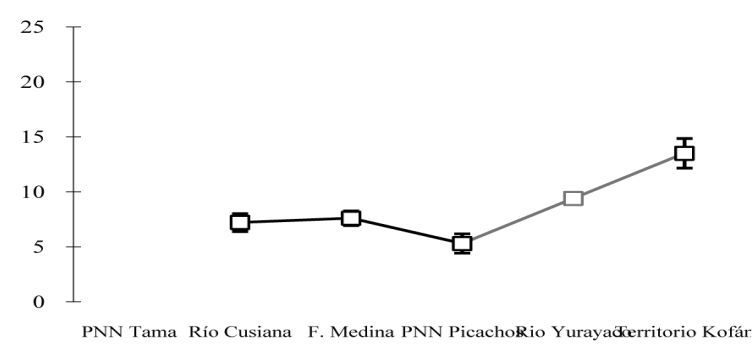

Rubiaceae Franja 1400-1600 m de altitud

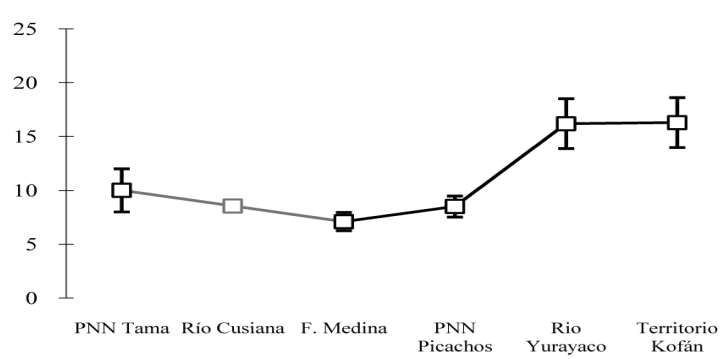

Rubiaceae Franja 900-1200 m de altitud

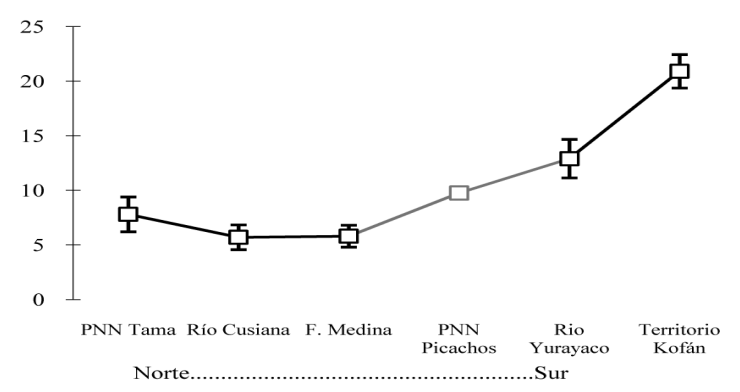

Figura 4. Comportamiento de la densidad de especies de Melastomataceae y Rubiaceae en el gradiente latitudinal en la voCO basado en submuestras (valores promedios de transectos de $80 \times 5 \mathrm{~m}$ ) 

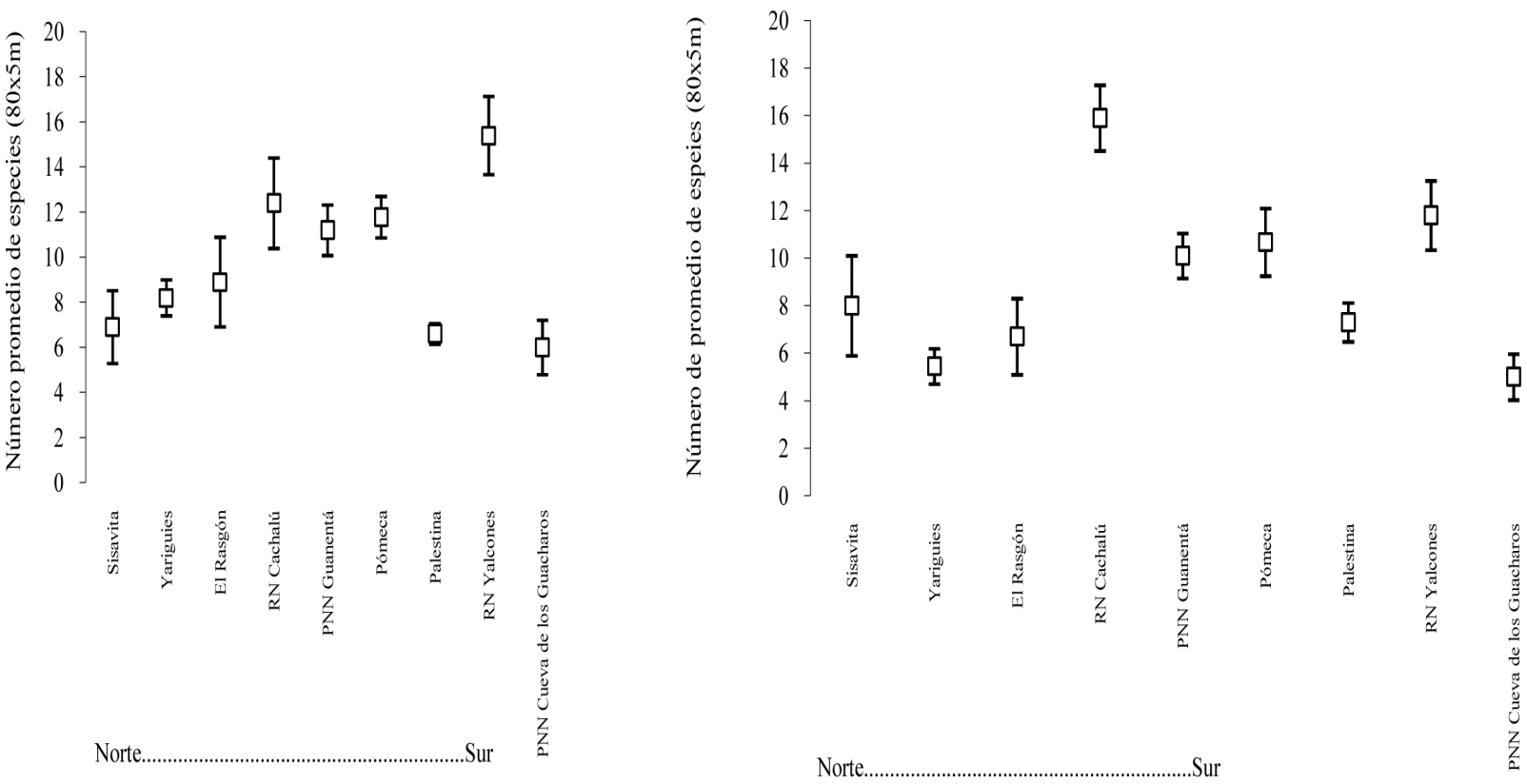

Figura 5. Comportamiento de la densidad de especies de Melastomataceae y Rubiaceae en el gradiente latitudinal en bosques de roble en la vertiente occidental de la $\mathrm{CO}$ basado en el valor promedio de la riqueza en transectos de $80 \mathrm{x}$ $5 \mathrm{~m}$

Considerando muestreos distanciados $250 \mathrm{~m}$ altitudinales (caso de Sisavita), se encontró que el IC fue superior al $60 \%$ entre muestras y que a medida que se incrementa la distancia altitudinal el IC aumenta hasta alcanzar un máximo alrededor de los 800-1000 m altitudinales de distancia entre muestras (Figura 6). En esta localidad, entre $\operatorname{los} 2500$ y $2800 \mathrm{~m}$ de altitud hubo un remplazamiento bastante fuerte (IC $=82$ y $89 \%$ ), lo que se puede asociar al cambio de tipos de vegetación Andina a Altoandina. Entre los 2300 y 3100 m hubo un recambio completo de especies de las dos familias.

Tabla 4. Valores de Índice de Complementariedad en porcentaje entre franjas separadas $500 \mathrm{~m}$ altitudinales en la voCO

\begin{tabular}{ccc}
\hline \multirow{2}{*}{$\begin{array}{c}\text { Altitudes } \\
(\mathrm{m})\end{array}$} & \multicolumn{2}{c}{ Índice de complementariedad \% } \\
\cline { 2 - 3 } & Melastomataceae & Rubiaceae \\
\hline $1000-1500$ & $54-95$ & $52-86$ \\
$1500-2000$ & $85-88$ & $68-88$ \\
$1000-2000$ & $93-100$ & $96-97$ \\
\hline
\end{tabular}

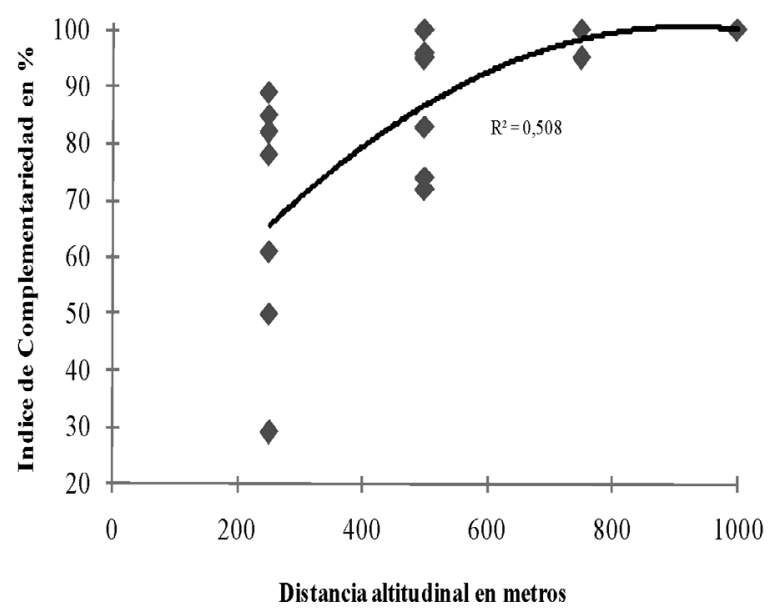

Figura 6. Comportamiento del recambio de especies (Índice de Complementariedad) con el incremento de la distancia altitudinal entre los 2000-3000 m altitudinales en Sisavita, Norte de Santander (Línea de tendencia polinómica)

\section{RECAMBIO DE ESPECIES EN EL GRADIENTE LATITUDINAL}

Para la voCO, los valores de complementariedad para las dos familias, independiente de la franja altitudinal, fueron superiores al $80 \%$ en una 
distancia no mayor de $250 \mathrm{~km}$ lineales (Tabla 5). Por ejemplo, entre Tama $1000 \mathrm{msnm}$ y Cusiana $1200 \mathrm{msnm}$ hay una distancia de $244 \mathrm{~km}$ en línea recta, y la complementariedad fue de $83 \%$ para Rubiaceae y $89 \%$ para Melastomataceae. Los sitios con menor complementariedad se encontraron entre el río Yurayaco (PNN Indiwasi, Caquetá) y el territorio Kofán (río Rumiyaco, Putumayo) con valores que oscilaron entre 75 y $79 \%$ (entre estas dos hay una distancia de $172 \mathrm{~km}$ en línea recta).

En las muestras localizadas en robledales, también se encontraron altos valores del Índice de Complementariedad (entre 45 y 100\%), indicando que no existe una comunidad similar de Melastomataceae y Rubiaceae asociada a este tipo de bosques (Tabla 6). Los sitios más cercanos entre sí comparten mayor número de especies para las dos familias.

\section{DISCUSIÓN}

\section{REPRESENTATIVIDAD}

Los inventarios locales presentaron alta representatividad, es decir que con el esfuerzo empleado se censaron la mayor parte de las especies esperadas en cada de punto muestreo. En el ámbito local siempre se presentó un número de especies con abundancia o frecuencia de aparición 1 o 2 (Uniques y Duplicates), las cuales se consideran especies raras para el muestreo; esta característica se ha observado en diferentes áreas en bosques húmedos tropicales y se puede atribuir al efecto de borde del muestreo. Si consideramos que cada especie tiene un óptimo desempeño a lo largo de un gradiente (Gauch, 1982), un muestreo siempre cubrirá un número de especies en sus óptimos y otra cantidad en las colas de sus óptimos, estas últimas siempre van a ser las especies raras de los muestreos.

Tabla 5. Valores del Índice de Complementariedad de Melastomataceae (parte superior de la matriz) y Rubiaceae (parte inferior de la matriz) en diferentes franjas altitudinales en la voCO

\begin{tabular}{lccccc}
\hline \multicolumn{5}{c}{ Localidades } \\
\hline Franja 1000-1200m & PNN Tama & Río Cusiana & F. Medina & Río Yurayaco & Territorio \\
& $1000 \mathrm{~m}$ & $1200 \mathrm{~m}$ & $1000 \mathrm{~m}$ & $950 \mathrm{~m}$ & Kofán 1000m \\
PNN Tama 1000m & - & 89 & 93 & 91 & 94 \\
Río Cusiana 1200m & 84 & - & 88 & 97 & 100 \\
F. Medina 1000m & 88 & 65 & - & 89 & 95 \\
Río Yurayaco 950m & 90 & 89 & 88 & - & 79 \\
T. Kofán 1000m & 92 & 94 & 0.89 & 81 & - \\
& & & & Río Yurayaco & Territorio \\
Franja 1400-1600m & PNN Tama & F. Medina & PNN Picachos & $1450 \mathrm{~m}$ & Kofán 1500m \\
& $1400 \mathrm{~m}$ & $1500 \mathrm{~m}$ & $1600 \mathrm{~m}$ & 94 & 95 \\
PNN Tama 1400m & - & 96 & 89 & 98 & 92 \\
F. Medina 1500m & 89 & - & 87 & - & 75 \\
PNN Picachos 1600m & 88 & 90 & - & 79 & - \\
Río Yurayaco 1450m & 90 & 89 & 94 & & \\
T. Kofán 1500m & 88 & 84 & 94 & & \\
& & & & & \\
Franja 2000m & Río Cusiana & F. Medina & PNN Picachos & El Mirador & \\
Río Cusiana 2000m & $2000 \mathrm{~m}$ & $2000 \mathrm{~m}$ & $2000 \mathrm{~m}$ & $2000 \mathrm{~m}$ & \\
F. Medina 2000m & - & 78 & 96 & 91 & \\
PNN Picachos 2000m & 76 & - & 93 & 92 & \\
El Mirador 2000m & 91 & 95 & - & 91 & \\
\hline & 89 & 94 & & & \\
\hline
\end{tabular}


Tabla 6. Valores del Índice de Complementariedad de Melastomataceae (parte superior de la matriz) y Rubiaceae (parte inferior de la matriz) entre localidades con bosque de roble en la $\mathrm{CO}$

\begin{tabular}{|c|c|c|c|c|c|c|c|c|c|c|c|c|c|}
\hline Localidades & 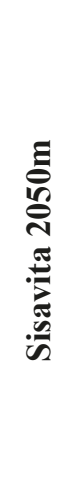 & 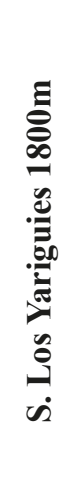 & 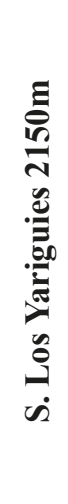 & 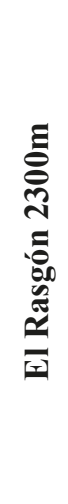 & 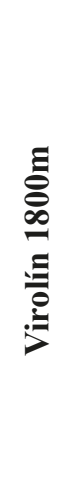 & 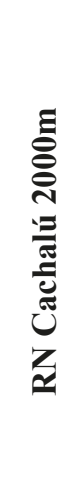 & 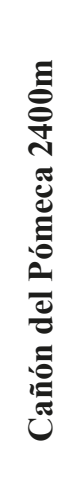 & 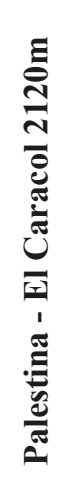 & 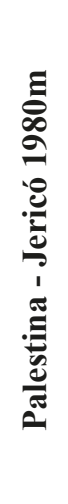 & 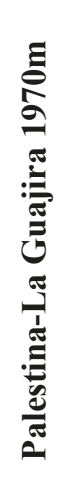 & 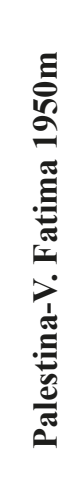 & 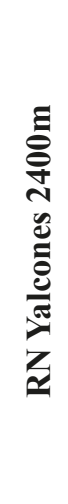 & 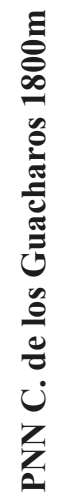 \\
\hline Sisavita $2050 \mathrm{~m}$ & - & 92 & 80 & 89 & 97 & 100 & 100 & 96 & 92 & 94 & 100 & 97 & 97 \\
\hline S. Los Yariguies $1800 \mathrm{~m}$ & 88 & - & 71 & 86 & 68 & 80 & 81 & 91 & 88 & 88 & 83 & 91 & 88 \\
\hline S. Los Yariguies 2150m & 93 & 75 & - & 83 & 71 & 82 & 75 & 92 & 97 & 97 & 100 & 97 & 90 \\
\hline El Rasgón 2300m & 68 & 86 & 96 & - & 86 & 91 & 91 & 96 & 93 & 97 & 93 & 97 & 97 \\
\hline Virolín 1800m & 75 & 79 & 87 & 81 & - & 45 & 79 & 97 & 97 & 95 & 97 & 95 & 94 \\
\hline RN Cachalú 2000m & 70 & 86 & 92 & 78 & 59 & - & 86 & 97 & 97 & 93 & 94 & 94 & 97 \\
\hline Cañon del Pómeca 2400m & 77 & 84 & 93 & 83 & 72 & 74 & - & 93 & 90 & 92 & 97 & 92 & 86 \\
\hline Palestina-El Caracol 2120m & 90 & 86 & 87 & 88 & 88 & 93 & 73 & - & 68 & 73 & 86 & 67 & 82 \\
\hline Palestina-Jericó 1980m & 85 & 85 & 91 & 83 & 83 & 90 & 72 & 58 & - & 76 & 73 & 83 & 79 \\
\hline Palestina-La Guajira 1970m & 90 & 83 & 83 & 89 & 88 & 93 & 83 & 50 & 47 & - & 71 & 70 & 84 \\
\hline Palestina-V. Fátima 1950m & 88 & 88 & 85 & 82 & 90 & 95 & 80 & 44 & 59 & 58 & - & 83 & 74 \\
\hline RN Yalcones 2400m & 85 & 92 & 97 & 91 & 86 & 81 & 67 & 48 & 69 & 68 & 72 & - & 87 \\
\hline PNN C. de los Guacharos 1800m & 82 & 86 & 96 & 81 & 68 & 78 & 74 & 88 & 78 & 89 & 82 & 84 & - \\
\hline
\end{tabular}

\section{RIQUEZA REGIONAL}

El inventario de estas dos familias en la Cordillera Oriental representa el 30 y el $23 \%$ de las especies de Melastomataceae y Rubiaceae respectivamente y documentadas para Colombia (Mendoza et al., 2004; Mendoza \& Ramírez, 2005; Tabla 3). El $22 \%$ de las especies inventariadas se colectaron libremente (no en parcelas) y en muchos de los casos corresponden a especies asociadas a hábitat abiertos como potreros y bordes de caminos. Para la CO y por encima de los $1000 \mathrm{~m}$ de altura pueden existir aproximadamente 320 especies de Melastomataceae (Mendoza \& Ramírez, 2005), por lo cual el inventario con este proyecto comprende alrededor del $88 \%$ de las especies, lo que representa un buen muestreo en el ámbito regional. Para la familia Rubiaceae no se tienen datos discriminados para la CO.

\section{VARIACIÓN DE LA RIQUEZA EN EL GRADIENTE ALTITUDINAL}

De acuerdo con los resultados, las dos familias tienen diferente comportamientos en el gradiente altitudinal, con un mayor decrecimiento de la riqueza específica con el incremento de la altitud en Rubiaceae. El $46 \%$ y el $61 \%$ de las especies de Melastomataceae del PNN Tama y Sisavita pertenecen al género Miconia, mientras que en 
Rubiaceae los géneros con mayor número de especies fueron Psychotria y Palicourea con el $47 \%$ y $48 \%$ del total de especies respectivamente. Esto indica que estos tres géneros son los que determinan en mayor proporción la tendencia de la riqueza de las dos familias en el gradiente altitudinal. La variación de los patrones de la riqueza de las dos familias puede ser interpretado como requerimientos ecológicos diferentes (Kessler et al., 2001).

Como se documenta en la introducción, las dos familias tienen estrategias de vida y evolutivas muy similares, no obstante, difieren en las estrategias de polinización y en los síndromes florales. Rubiaceae tiene flores de corola tubular con disco nectarífero, donde la recompensa a los polinizadores es el néctar (Taylor, 1996; Mendoza et al., 2004); Palicourea es principalmente polinizado por colibríes y Psychotria por insectos lepidópteros nocturnos, algunas abejas y en menor proporción colibríes (G. Stiles, com. pers.). Por otra parte, Melastomataceae tiene flores de corolas abiertas sin disco nectarífero, donde la recompensa a los polinizadores es principalmente el polen y los tejidos del conectivo de la antera; Miconia, en especial, es polinizada por insectos himenópteros (abejas) y mariposas diurnas (Renner, 1989). En términos generales, Rubiaceae es predominantemente polinizada por aves mientras que Melastomataceae predomina la polinización por abejas (Renner, 1989; Bawa, 1990). Estas diferencias son las más contrastantes entre las dos familias y, aunque no es concluyente, se plantea que la polinización puede ser determinante para la variación de la riqueza en la escala del gradiente altitudinal.

El comportamiento de la riqueza con la altitud tiende a ser monotónica para las dos familias, en especial, si se considera que los valores de la riqueza no presentan diferencias significativas entre los 1000 y $2500 \mathrm{~m}$ de altitud. A partir de los $2500 \mathrm{~m}$ de altitud se encuentran amplias diferencias, para Rubiaceae y para Melastomataceae, a partir de los $2800 \mathrm{~m}$ de altitud. Un patrón monotónico similar se ha documentado para Bromeliaceae en los Andes de Bolivia (Kessler et al., 2001); sin embargo, para
Melastomataceae Kessler (2000) documenta un patrón hump-shaped igualmente para los Andes de Bolivia. Esto indica que los patrones de la riqueza varían entre regiones y entre grupos y dependen en parte de las condiciones ambientales y la escala. No es lo mismo establecer un gradiente altitudinal en zonas montañosas colindantes con zonas árida y zonas montañosas colindantes con zonas húmedas; también depende del rango altitudinal estudiado, pues como ocurre en este caso, solo se observó una parte del gradiente altitudinal. El trabajo de Kessler (2000) considera zonas bajas áridas y considera un gradiente entre los 500 y $2500 \mathrm{~m}$ de altitud, mientras que en este trabajo las zonas bajas colindantes corresponden a bosques húmedos y fue a partir de los $1000 \mathrm{~m}$ de altitud. Es posible que si se consideran muestreos por debajo de los $1000 \mathrm{~m}$ de altitud y en franjas altitudinales más estrechas, el comportamiento de la riqueza cambie.

\section{VARIACIÓN DE LA RIQUEZA EN EL GRADIENTE LATITUDINAL}

Aunque la desigualdad en magnitud del inventario no permite hacer comparaciones detalladas entre las dos vertientes de la $\mathrm{CO}$, es evidente que la riqueza de especies tiene diferente comportamiento entre las vertientes, el cual se puede asociar a biotas e historias de evolución distintas.

La vertiente occidental de la $\mathrm{CO}$ y parte de la vertiente del río Zulia fueron marcadas notablemente por varias migraciones de especies de roble (Quercus) que se dieron en el norte de los Andes hace cerca de 1 ma (Van der Hammen, 1974; Van der Hammen \& Cleef, 1983; Palacios \& Fernández, 2006). La mayor parte de los bosques andinos en estos flancos se encontraban, hasta hace unos siglos, cubiertos por grandes extensiones de robledales, que no alcanzaron a colonizar zonas sobre la voCO, excepto por una pequeña sección entre los departamento de Huila y Caquetá, la cual baja hasta los $1600 \mathrm{~m}$ de altitud. Probablemente, los bosques de roble colonizaron los flancos internos de las cordilleras occidental y oriental los cuales fueron afectadas por deposiciones de cenizas volcánicas $\mathrm{y}$ posteriormente fueron enriquecidos por biotas 
circundantes hasta alcanzar las configuraciones actuales de diversidad. Es posible que esto haya generado un efecto de homogenización que hizo que se dieran magnitudes de la riqueza similares a lo largo de la franja de vegetación alrededor de los $2000 \mathrm{~m}$ de altitud en la vertiente occidental del CO.

En la voCO, a diferencia de las otras vertientes, confluyen dos grandes zonas biogeográficas como son el noroccidente de la Amazonia y la Orinoquia. El incremento de la riqueza de especies hacia el Ecuador geográfico puede ser consecuencia de la confluencia de biotas Andinas y Amazónicas, que por sobreposición genera una mayor riqueza entre los 1000 y $2000 \mathrm{~m}$ de altitud. A lo largo del piedemonte de la voCO se encontraron abundantes elementos de procedencia amazónica que confirman un corredor de vegetación amazónica (J. Hernández-Camacho, com. pers.); este corredor enriqueció el piedemonte de la voCO, no obstante, es posible que el tiempo y la intensidad de interacción de las dos biotas fueron mayores en los departamentos del Caquetá y Putumayo (sur del área de estudio) y esto sea la posible causa de los altos valores de la riqueza de Melastomataceae y Rubiaceae en esta zona.

\section{RECAMBIO DE ESPECIES EN EL GRADIENTE ALTITUDINAL}

Estos resultados indican grandes reemplazos de especies de las dos familias entre franjas altitudinales estrechas $(250-500 \mathrm{~m})$ y un reemplazo casi completo entre franjas distanciadas $1000 \mathrm{~m}$ altitudinales (Figura 7). El recambio de especies es un fenómeno atribuible a los drásticos cambios de las condiciones ambientales con el incremento de la altitud, razón por la cual es de esperarse diferentes comunidades en franjas altitudinales. En la voCO, las abruptas pendientes y la directa intersección de vientos y nubosidad proveniente de las llanuras amazónica y de la Orinoquia, originan franjas de tipos de vegetación más estrechas y en altitudes más bajas que en las vertientes internas de las cordilleras. La consecuencia de esto es un mayor recambio de especies en distancias altitudinales pequeñas.

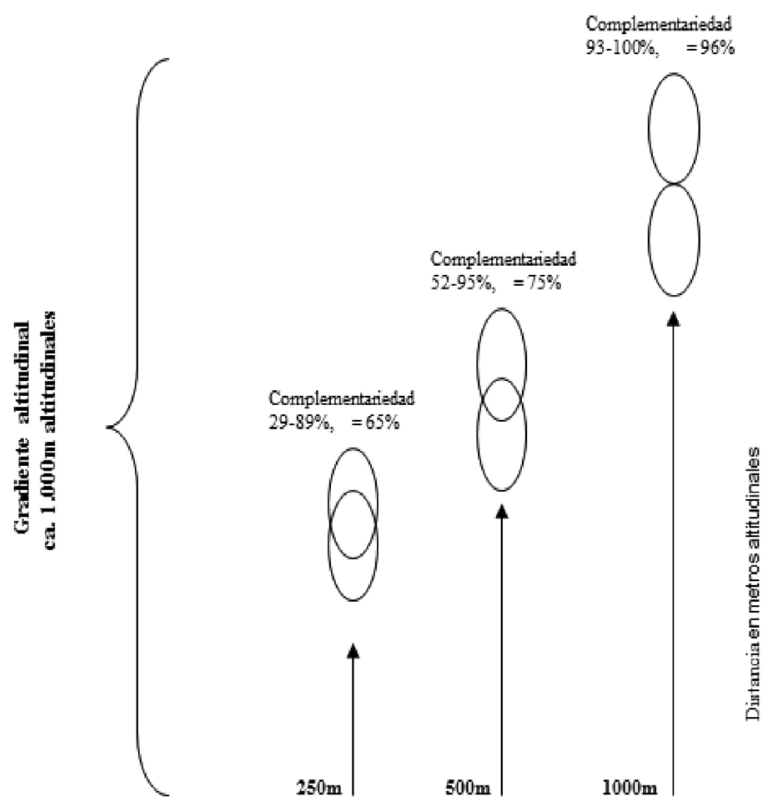

Figura 7. Modelo del comportamiento del recambio de especies basado en el Índice de Complementariedad en el gradiente altitudinal en la voCO y Sisavita (Norte de Santander).

\section{RECAMBIO DE ESPECIES EN EL GRADIENTE LATITUDINAL}

Similar al gradiente altitudinal, en la voCO el recambio de especies fue proporcional a la distancia, pero existe una distancia determinada a partir de la cual la complementariedad es superior al $80 \%$ y así se incremente esta, la complementariedad permanece igual o aumenta pero levemente (Figura 8).

Las magnitudes del recambio de especies en la voCO, plantean que existen comunidades de Melastomataceae y Rubiaceae bastante variables en composición en el gradiente latitudinal. No obstante, emergen algunos interrogantes que cuestionan si los resultados encontrados representan exactamente un patrón natural. Cerca del $60 \%$ de las especies identificadas de las dos familias se encuentran distribuidas en otras regiones y cordilleras del norte de los Andes, es decir se distribuyen irregularmente en otras zonas del norte de los Andes. En Melastomataceae y Rubiaceae, y de acuerdo con las listas que se manejan para Colombia (Mendoza et al., 2004; 


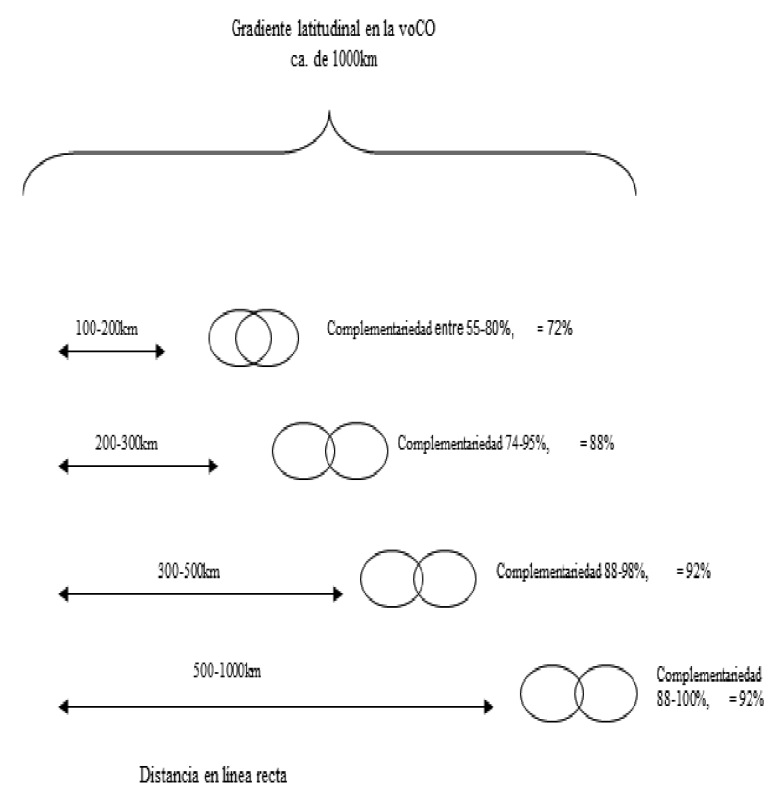

Figura 8. Modelo del comportamiento del recambio de especies basado en el Índice de Complementariedad en el gradiente latitudinal en la voCO.

Mendoza \& Ramírez, 2005), son pocas las especies localmente endémicas y prevalecen las especies endémicas a grandes regiones como por ejemplo el Chocó biogeográfico, norte de los Andes o Escudo Guayanés.

Es probable que los niveles del recambio de especies encontrados en el gradiente latitudinal sean de menor magnitud considerando que localmente se contó con muestras pequeñas pero que arrojaron buenas curvas de acumulación. La explicación más idónea a esto se le puede atribuir a la distribución irregular de las especies asociadas a condiciones de microhábitats. Esto quiere decir que localmente la mayor parte de las especies solo crecen en determinados microhábitas y presentan poblaciones a lo largo de grandes áreas (cordilleras). Esto ocasiona que al muestrear un punto o un microhábitat en una localidad se obtengan buenos muestreos, no obstante, al repetir esto en otra localidad posiblemente no estaremos en el mismo tipo de microhábitat y con seguridad la composición de especies será muy distinta.

Lo anterior plantea un grave problema de diseño de los inventarios estandarizados en la región andina, pues la mayor parte de los estudios establecen puntos de muestreos sin considerar esta variación local dada las dificultades para hacerlo. En la figura 9 se muestra la relación entre el número de especies, el número de localidades en la voCO y la frecuencia de aparición. De acuerdo con esta figura, la mayoría de las especies en la voCO se encontraron en pocas localidades (menos de tres) y con bajas frecuencias de aparición, lo que es un indicio de la distribución irregular de las especies.

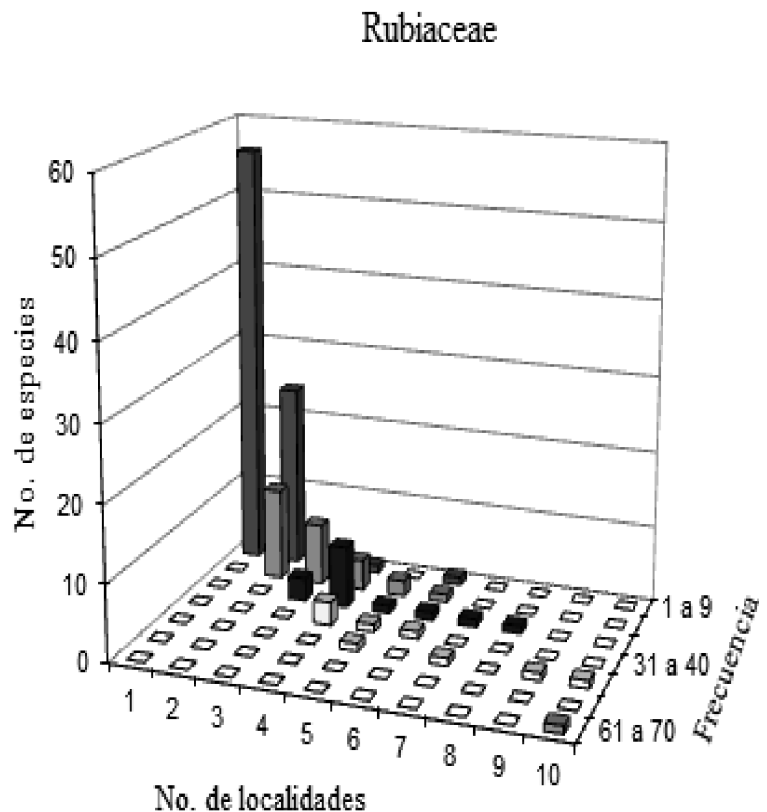

\section{Melastomataceae}

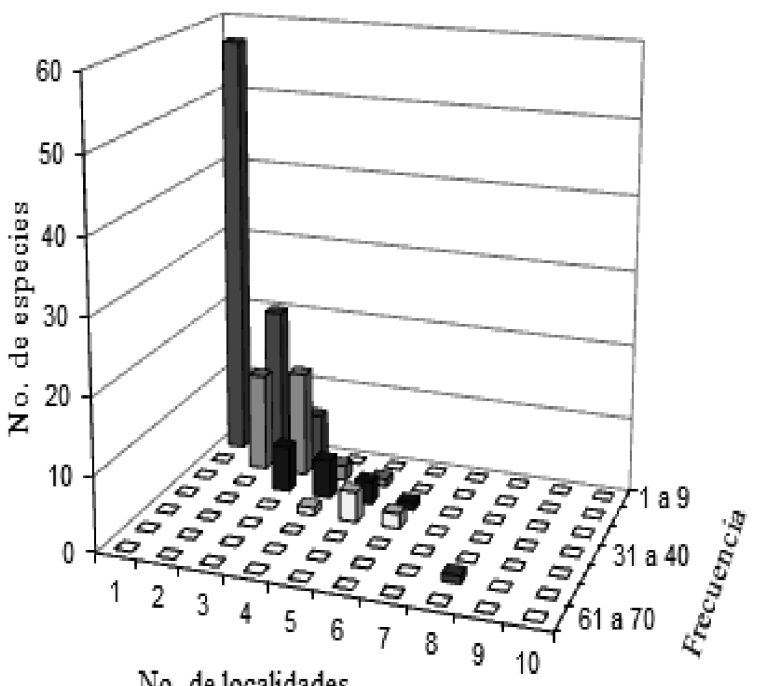

No. de localidades

Figura 9. Relación del número, la distribución y abundancia de las especies de Melastomataceae y Rubiaceae en la voCO. 
En las muestras localizadas en robledales, los altos valores del recambio de especies de las dos familias indican que los bosques de roble no están asociados a una flora de Melastomataceae y Rubiaceae específica. De lo anterior se puede inferir que la historia de colonización de las dos especies de robles en el norte de los Andes fue independiente al de las familias Melastomataceae y Rubiaceae. Se puede decir que son pocos los elementos que están asociados a las especies de roble en el norte de los Andes y que reflejen una historia evolutiva compartida (eg. Alfaroa colombiana de la familia Juglandaceae). Los resultados muestran que los sitios entre más cercanos comparten mayor número de especies, lo que refleja que buena aparte de las especies de Melastomataceae y Rubiaceae encontradas en robledales provienen de zonas cercanas geográficamente. Esto indica que la actual configuración de Melastomataceae y Rubiaceae de los bosques de roble corresponde a grupos provenientes de los bosques andinos mixtos aledaños que han enriquecido este tipo de comunidad.

\section{CONCLUSIONES}

El presente trabajo se constituye en el primer intento de cuantificar la variación de la riqueza y recambio de especies en gradientes en la cordillera Oriental de Colombia.

La riqueza de especies de las dos familias disminuyó con el incremento de la altitud, no obstante, en Rubiaceae se presentó un mayor decrecimiento en comparación con Melastomataceae. La riqueza para las dos familias presentó un patrón monotónico, que se puede considerar atípico, sin embargo, se plantea que puede ser producto de la escala de trabajo, pues el intervalo altitudinal fue a partir de los $1000 \mathrm{~m}$ de altitud.

En el gradiente latitudinal la riqueza específica fue mayor en las localidades al sur de la Cordillera Oriental y se plantea que en la franja entre los 1000 y $2000 \mathrm{~m}$ de altitud en la voCO; este parámetro aumenta a medida que nos acercamos al Ecuador geográfico. En el flanco occidental de la $\mathrm{CO}$ no se encontró una tendencia de cambio de la riqueza específica en bosque de roble. Se plantea hipotéticamente que distintos procesos evolutivos de diferentes biotas determinaron las actuales tendencias y los niveles de diversidad en los diferentes flancos de la CO: la confluencia de grandes biotas en la voCO y los procesos de migración de especies de Quercus posiblemente favorecidos por vulcanismo fueron los factores determinantes de la diversidad actual en plantas en la CO entre los 1000 y 2000 m de altitud.

En la voCO se encontró un recambio grande de especies en el gradiente altitudinal, indicando que dos puntos distanciados $1000 \mathrm{~m}$ altitudinales presentan comunidades de Melastomataceae y Rubiaceae completamente diferentes.

El recambio de especies en el gradiente latitudinal presentó valores superiores al $88 \%$ del IC en distancia iguales o superiores a $250 \mathrm{~km}$ lineales. Sin embargo, la magnitud del recambio puede ser menor ya que pueden existir problemas metodológicos por causa de las muestras pequeñas y la distribución irregular de las especies asociada a condiciones de microhábitats.

\section{CONSIDERACIONES PARA LA CONSERVACIÓN}

Los resultados encontrados en este trabajo muestran que las unidades de conservación en la $\mathrm{CO}$, en especial en la voCO, serían representativas de la biota andina si consideran gradientes altitudinales completos (superiores a $1000 \mathrm{~m}$ ), se distribuyeran homogéneamente a lo largo de la vertiente (distanciadas 250 a $300 \mathrm{~km}$ lineales equidistantes unas de otras) y se ubicaran a partir de los 1000-1200 m de altitud. Ocho de las áreas de conservación cubren gradientes altitudinales completos excepto por el PNN Pisba, el cual ameritaría una mejor conexión con zonas de Bosque Subandino.

Latitudinalmente, los nueve parques se encuentran distribuidos entre las fronteras con Venezuela y Ecuador, más o menos equidistantes unos de otros. No obstante, existen regiones que abarcan entre 700 
Tabla 7. Áreas de conservación en la voCO, Colombia (Villegas, 2006). PNN, Parque Nacional Natural; SFF, Santuario de Flora y Fauna

\begin{tabular}{lccl}
\hline Área de conservación & $\begin{array}{c}\text { Rango altitudinal } \\
\text { msnm }\end{array}$ & Extensión ha. & \multicolumn{1}{c}{ Departamentos } \\
\hline PNN Tamá & $350-3400$ & 48000 & N. Santander, Boyacá \\
PNN El Cocuy & $600-5330$ & 306000 & Boyacá, Casanare, Arauca \\
PNN Pisba & $2000-3800$ & 45000 & Boyacá, Casanare \\
PNN Chingaza & $800-4020$ & 76600 & Cundinamarca, Meta \\
PNN Sumapaz & $1500-4300$ & 154000 & Cundinamarca, Huila, Meta \\
PNN Cordillera de Los Picachos & $250-3800$ & 294319 & Meta, Caquetá \\
PNN Alto Fragua Indiwasi & $900-3725$ & 77336 & Huila, Caquetá \\
PNN Serranía de & & & Huila, Cauca, Caquetá, \\
Los Churumbelos & $400-3000$ & 97189 & Putumayo \\
SFF Orito Ingi-ande & $700-3300$ & 10240 & Nariño, Putumayo \\
\hline
\end{tabular}

y $1000 \mathrm{~km}$ lineales en los que no existen áreas de conservación como son las zonas entre los PNN de Pisba y Chingaza (piedemonte de los departamentos de Boyacá y Casanare), y entre los PNN cordillera de Los Picachos e Indiwasi (piedemonte central del departamento de Caquetá). Estas dos zonas ameritarían nuevas áreas de conservación, en especial, entre los 1000 y 2000 m de altitud.

El ecosistema de vegetación Bosque Subandino se encuentra supremamente degradado en los flancos internos de las tres cordilleras en Colombia, por lo que los bosques de la voCO representan una oportunidad única para conservar este tipo de vegetación. En la voCO existen nueve áreas de conservación que cubren una extensión de más de 1.1 millones de ha (Tabla 7). De esta área, cerca del $60 \%$ corresponde a zonas de bosque andinos entre los 1000 y $2800 \mathrm{~m}$ de altitud, y de estas, a su vez, aproximadamente el $40 \%$ corresponde a zonas de Bosque Subandino entre los 1000 y $2000 \mathrm{~m}$ de altitud (cerca del 25\% de toda el área de conservación). Si se consideran estas cifras, es importante que cualquier iniciativa de conservación en la voCO considere aumentar el porcentaje cobertura del bosque Subandino.

El $57 \%$ del total del área de conservación en la voCO se concentra en la zona norte a partir del departamento del Meta. Si se considera que hacia el sur de la voCO hay un incremento progresivo de la riqueza de especies, es importante que el área total de conservación en Caquetá y Putumayo fuera mayor o equiparable al de la zona norte de la voCO.

\section{AGRADECIMIENTOS}

Expreso mis agradecimientos por el apoyo a este trabajo a: Ana María Umaña, Adriana Prieto, Cristian Samper, Héctor Villareal, Fernando Gast, Mauricio Álvarez, Fabio Quevedo†, ex funcionarios del Instituto Alexander von Humboldt; a las auxiliares del herbario Federico Medem (FMB) Aura Robles y Sandra Medina; a los investigadores acompañantes de las diferentes salidas de campo Zuly Martínez, Ferney Pita, Bernardo Ramírez, Diego Macías, Julio Betancur, Daniel Dávila, Robinson Galindo, Julián Cadena, Carolina Gantiva, Judit A. Ávila, Ariel Dueñas, Gustavo Luna, Roberto Sánchez y Ledy Pérez; a Charlotte Taylor por su colaboración en la identificación de colecciones de Rubiaceae; al Instituto Alexander von Humboldt; a los herbarios COL (Herbario Nacional Colombiano) y FMB; a COLCIENCIAS por el apoyo económico a este proyecto. 


\section{REFERENCIAS BIBLIOGRÁFICAS}

Anderson, L. (1993). Rubiaceae-introduction: Rubiacae-Anthospermeae. En G. Harling \& L. Andersson (eds.), Flora of Ecuador, No. 47, (pp. 1-38). Stockholm: University of Göteborg \& Riksmuseum.

Anderson, L., \& Taylor, C.M. (1994). Rubiaceae-Cinchoneae-Coptosapelteae. En G. Harling \& L. Andersson (eds.), Flora of Ecuador, No. 50, (pp. 1-114). Stockholm: University of Göteborg \& Riksmuseum.

Armenteras, D., Cadena-D, C., \& Moreno, R.P. (2007). Evaluación del estado de los bosques de niebla y de la meta 2010 en Colombia. Bogotá: Instituto de Investigación de Recursos Biológicos Alexander von Humboldt. 72 p.

Bawa, K.S. (1990). Plant-pollinator interactions in tropical rain forest. Annual Review of Ecology, Evolution and Systematic, 21, 399-422.

Berry, P., Gröger, A., Holst, B.K., Morley, T., Michelangeli, F., Luckana, N.G., Almeda, F., Renner, S., Freire-Fierro, A., Robinson, O.R., \& Yatskievych, K. (2001). Melastomataceae. En J.A. Steyermark, P. Berry, K. Yatskievych \& B.K. Holst (eds.), Flora of the Venezuelan Guayana, Vol. 6, (pp. 263-528). Saint Louis: Missouri Botanical Garden.

Boyle, B.L. (1996). Changes on altitudinal and latitudinal gradients in neotropical montane forest. (Unpublished Dissertation School). Saint Louis: Washington University. 275 p.

Cardelús, C.L., Colwell, R.K., \& Watkins Jr, J.E. (2006). Vascular epiphyte distribution patterns: explaining the mid-elevation richness peak. Journal of Ecology, 94, 144-156.

Cleef, A.M., Rangel, J.O., \& Salamanca, S. (2003). The andean rain forest of the Parque Los Nevados transects, Cordillera Central, Colombia. En T. van der Hammen \& A.G. dos
Santos (eds.), La Cordillera Central colombiana - Transecto Los Nevados, Studies on Tropical Andean Ecosystems, Vol. 5, (pp. 79-141). Berlin-Stuttgart: Cramer Borntraeger.

Colwell, R.K. (2005). EstimateS: Statistical estimation of species richness and shared species from sample, Versión 7.5. Persistent. Recuperado de http://purl.oclc.org/estimates.

Colwell, R.K., \& Coddington, J. (1994). Estimating terrestrial biodiversity through extrapolation. Philosophical Transactions of the Royal Society of London, 345, 101-118.

Cuatrecasas, J. (1958). Aspectos de la vegetación natural de Colombia. Revista de la Academia Colombiana de Ciencias, 10, 221-263.

Flórez, A. (2004). Colombia: evolución de sus relieves y modelados. Bogotá: Universidad Nacional de Colombia, Facultad de Ciencias Humanas, Departamento de Geografía. 240 p.

Gaston, K.J., Williams, P.H., Eggleton, P., \& Humphries, C.J. (1995). Large scale patterns of biodiversity: Spatial variation in family richness. Proceedings of the Royal Society: Biological Sciences, 260, 149-154.

Gauch, H. (1982). Multivariate analysis in community ecology. Cambridge: Cambridge University Press. 298 p.

Instituto Geográfico Agustín Codazzi [IGAC]. (1982). Atlas regional Andino. Bogotá: Instituto Geográfico Agustín Codazzi. 168 p.

Instituto Geográfico Agustín Codazzi [IGAC]. (2003). Atlas de Colombia (5 $5^{\text {ta }}$ ed.). Bogotá: Instituto Geográfico Agustín Codazzi. 321 p.

Kappelle, M., \& Zamora, N. (1995). Change in woody species richness along an altitudinal gradient in Talamanca montane Quercus forest, Costa Rica. En S.P. Churchill, H. Baslev, 
E. Forero \& J. L. Luteyn (eds.), Biodiversity and conservation of Neotropical montane forest (pp. 135-148). New York: The New York Botanical Garden.

Kessler, M. (2000). Elevational gradients in species richness and endemism of selected plant groups in the central Bolivian Andes. Plant Ecology, 149, 181-193.

Kessler, M. (2002). The elevational gradient of Andean plant endemism: varying influences of taxon-specific traits and topography at different taxonomic levels. Journal of Biogeography, 29, 1159-1165.

Kessler, M. (2002a). Range size and its ecological correlates among the pteridophytes of Carrasco National Park, Bolivia. Global Ecology \& Biogeography, 11, 89-102.

Kessler, M., Herzog, S.K., Fjeldsa, J., \& Bach, K. (2001). Species richness and endemism of plant and bird communities along two gradients of elevation, humidity and land use in the Bolivia Andes. Diversity and Distributions, 7, 61-77.

Kessler, M., Kluge, J., Hemp, A., \& Ohlemüller, R. (2011). A global comparative analysis of elevational species richness patterns of ferns. Global Ecology and Biogeography, 20(6), 868-880.

Kitayama, K. (1992). An altitudinal transect study of the vegetation of Mount Kinabalu, Borneo. Plant Ecology, 102, 149-171.

Kitayama, K., \& Mueller-Dombois, D. (1994). An altitudinal transect analysis of the windward vegetation on Haleakala, a Hawaiian island mountain: (2) Vegetation zonation. Phytocoenologia, 24, 135-154.

Koleff, P., \& Gaston, K.J. (2001). Latitudinal gradients in diversity: real patterns and random models. Ecography, 24, 341-351.
Krömer, T., Kessler, M., Gradstein, S.R., \& Acebey, A. (2005). Diversity patterns of vascular epiphytes along an elevational gradient in the Andes. Journal of Biogeography, 32, 1799-1809.

Lieberman, D., Lieberman, M., Peralta. R., \& Harsthorn, G. (1996). Tropical forest structure and composition on a large-scale altitudinal gradient in Costa Rica. Journal of Ecology, 34, 137-152.

Lozano, G., Ruiz, N., González, F.A., \& Murillo, M.T. (1996). Diversidad vegetal del Parque Nacional de Munchique, Cauca, Colombia (entre 1800 y $3050 \mathrm{~m}$ de altitud). Biblioteca José Jerónimo Triana, 13, 9-64.

Mendoza, H., Ramírez, B., \& Jiménez, L.C. (2004). Rubiaceae de Colombia - Guía ilustrada de géneros. Bogotá: Instituto Alexander von Humboldt. 321 p.

Mendoza, H., \& Ramírez, B. (2005). Lista preliminar de especies de Melastomataceae y Memecylaceae para Colombia. Bogotá: Instituto de Investigación de Recursos Biológicos Alexander von Humboldt, Universidad del Cauca. 23 p.

Mendoza, H., \& Ramírez, B. (2006). Guía ilustrada de géneros de Melastomataceae y Memecylaceae de Colombia. Bogotá: Instituto Alexander von Humboldt. 300 p.

Nathan, J.S. (2002). Elevational gradients in ant species richness: area, geometry, and rapaport's rule. Ecogeography, 25, 25-32.

Palacios, J.D., \& Fernández, J.F. (2006). Estado de la investigación genética en la conservación de los robles (Fagaceae) en Colombia. En C. Solano \& V. Vargas (eds.), Memorias del I Simposio internacional de roble y ecosistemas asociados (pp. 57-72). Bogotá: Fundación Natura - Pontificia Universidad Javeriana. 
Rahbek, C. (1995). The elevational gradient of species richness: a uniform pattern? Ecography, 18, 200-205.

Rangel, O. (1991). Vegetación y ambiente en tres gradientes montañosos en Colombia (Tesis inédita de doctorado). Ámsterdam: Universidad de Ámsterdam. 349 p.

Rangel, O., Cleef, A.M., Van der Hammen, T., \& Jaramillo, R. (1982). Tipos de vegetación en el transecto Buritaca-La Cumbre, Sierra Nevada de Santa Marta (entre 0 y 4100m). Colombia Geográfica, 10, 1-18.

Rangel, O., \& Lozano, G. (1986). Un perfil de vegetación entre La Plata (Huila) y el Volcán Puracé. Caldasia, 14, 503-547.

Renner, S.S. (1989). Reproduction and evolution in some genera of neotropical Melastomataceae. Memories of the New York Botanical Garden, 55, 143-152.

Sanders, N.J., \& Rahbek, C. (2012). The patterns and causes of elevational diversity gradients. Ecography, 35, 1-3.

Steyermark, J.A. (1974). Rubiaceae. En T. Lasser (ed.), Flora de Venezuela, No. 9(1-3), (pp. 1-2070). Caracas: Instituto Botánico, Dirección de Recursos Naturales Renovables, Ministerio de Agricultura y Cría.

Taylor, C.M. (1996). Overview of the Psychotrieae (Rubiaceae) in the Neotropics. Opera Botanica Belgica, 7, 261-270.

Van der Hammen, T. (1958). Estratigrafía del Terciario y Maestrichtiano continentales y tectogénesis de los Andes colombianos - Colombia. Boletín Geológico, 6, 67-128.

Van der Hammen, T. (1974). The pleistocene changes of vegetation and climate in tropical South America. Journal of Biogeography, 1, 3-26.
Van der Hammen, T., \& Cleef, A.M. (1983). Trigonobalanus and the neotropical amphipacific element in the north Andean forest. Journal of Biogeography, 10, 437-440.

Van der Hammen, T., Wermeer, J.H., \& Van Dommelen, H. (1983). Palynological record of the up-heaval of the Northern Andes: A study of the pliocene and lower quaternary of the colombian eastern cordillera and the early evolution of its high-Andean biota. Review of Paleobotany and Palynology, 16, 1-122.

Van der Hammen, T., \& Rangel-Ch, J.O. (1997). El estudio de la vegetación en Colombia. En O. Rangel, P.D. Lowy \& M. Aguilar (eds.), Colombia, Diversidad Biótica II, Tipos de vegetación (pp. 17-57). Bogotá: Instituto de Ciencias Naturales-Universidad Nacional de Colombia, Instituto de Hidrología, Meteorología y de Estudio Ambientales.

Vázquez, J.A., \& Givinish, T.J. (1998). Altitudinal gradients in tropical forest composition, structure, and diversity in the Sierra de Manantlán. Journal of Ecology, 86, 99-1020.

Villarreal, H., Álvarez, M., Córdoba, S., Escobar, F., Fagua, G., Gast, F., Mendoza, H., Ospina M., \& Umaña, A.M. (2004). Manual de métodos para el desarrollo de inventarios de biodiversidad. Bogotá: Instituto Alexander von Humboldt - Programa de Inventarios de Biodiversidad. $236 \mathrm{p}$.

Villegas, B. (ed.). (2006). Colombia Parques Naturales. Bogotá: Villegas Editores. 447 p.

Wolf, J.H. (1993). Diversity patterns and biomass of epiphytic bryophytes and lichens along an altitudinal gradient in the northern Andes. Annals of the Missouri Botanical Garden, 80, 928-960.

Wolf, J.H. (2003). Diversity and ecology of epiphytic communities in the Cordillera Central, 
Colombia. En T. Van der Hammen \& A.G. Dos Santos (eds.), La Cordillera Central colombiana - Transecto Los Nevados, Studies on Tropical Andean Ecosystems, Vol. 5, (pp. 453-502). Berlin-Stuttgart: Cramer (Borntraeger).

Wurdack, J.J. (1973). Melastomataceae (Memecyleae by T. Morley). En T. Lasser (ed.),
Flora de Venezuela, No. 8, (pp. 1-819). Caracas: Instituto Botánico, Ministerios de Agricultura y Cría.

Wurdack, J.J. (1980). Melastomataceae. En G. Harling \& B. Sparre (eds.), Flora of Ecuador, No. 13, (pp. 1-405). Stockholm: University of Goteborg, Swedish Natural Science Research Council. 
Anexo 1. Lista de especies de Melatomataceae y Rubiaceae inventariadas en parcelas en la Cordillera Oriental y datos de abundancia (frecuenca de aparición) HMC (Humberto Mendoza Cifuentes), AP (Adriana Prieto), GL (Gustavo Luna), ZM (Zuly Martinez)

\begin{tabular}{|c|c|c|c|c|c|c|c|c|c|c|c|c|c|c|c|}
\hline \multirow{3}{*}{$\begin{array}{l}\text { Familia } \\
\text { Especie }\end{array}$} & \multicolumn{7}{|c|}{ Vertiente Oriental de la Cordillera Oriental } & \multirow{2}{*}{ 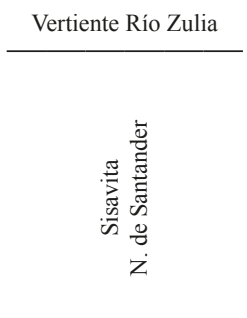 } & \multicolumn{7}{|c|}{ Vertiente Río Magdalena } \\
\hline & 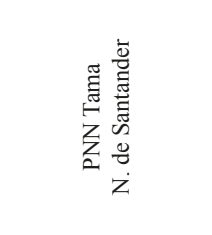 & 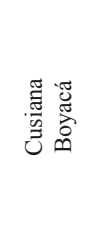 & 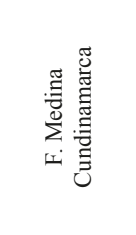 & 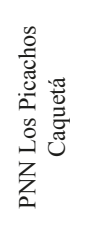 & 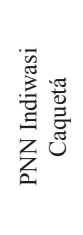 & 营离 & 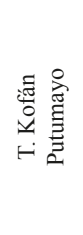 & & 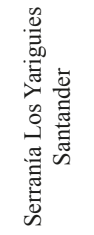 & 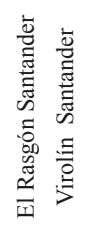 & 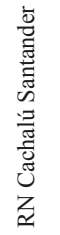 & 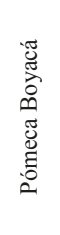 & 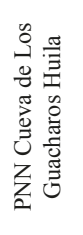 & 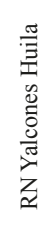 & 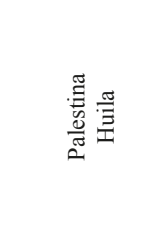 \\
\hline & 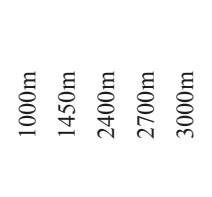 & ఏ్亏 & 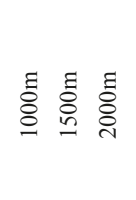 & 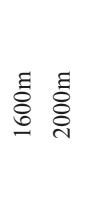 & 音 㝕 & छ్ & 咅 & 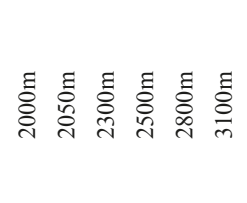 & 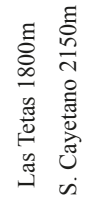 & 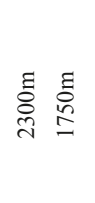 & छั & 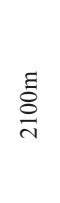 & 志 & 志 & 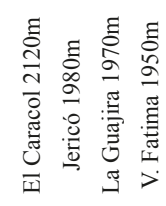 \\
\hline
\end{tabular}

MELASTOMATACEAE

Aciotis purpurascens

Adelobotrys adcenden

Adelobotrys tessmanni

Adelobotrys sp 8969 HMC

Axinaea macrophylla

Blakea bracteata

Blakea calyptrata

Blakea cuatrecasii

Blakea eriocalyx

$\begin{array}{lllll}13 & 7 & 36 & 45 & 13\end{array}$

Blakea granatensis 


\begin{tabular}{|c|c|c|c|c|c|c|c|c|c|c|c|c|c|c|c|c|}
\hline \multirow{3}{*}{$\begin{array}{l}\text { Familia } \\
\text { Especie }\end{array}$} & \multicolumn{7}{|c|}{ Vertiente Oriental de la Cordillera Oriental } & \multirow{2}{*}{ 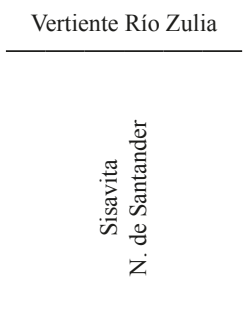 } & \multicolumn{8}{|c|}{ Vertiente Río Magdalena } \\
\hline & 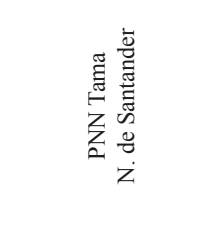 & 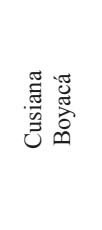 & 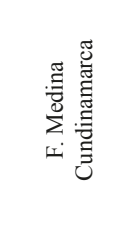 & 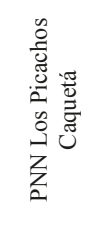 & 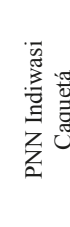 & 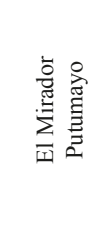 & 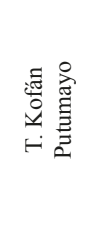 & & 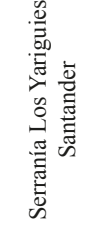 & 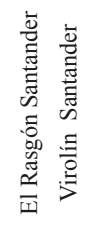 & 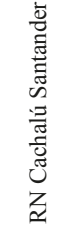 & 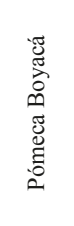 & 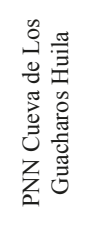 & 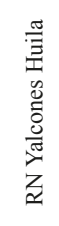 & & 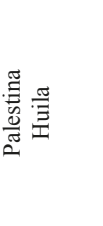 \\
\hline & 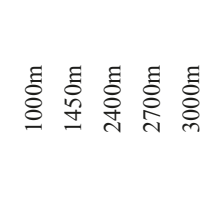 & 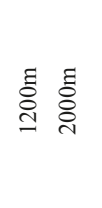 & ह⿱艹 & 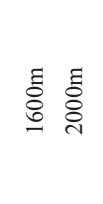 & छूँ & క్రి & 咅 哭 & 悹 悹 & 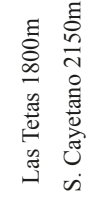 & 蒿 & ఫ్ & 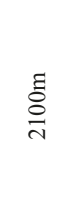 & 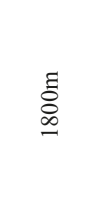 & 㤐 & 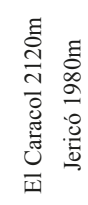 & 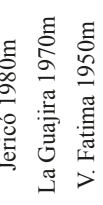 \\
\hline Blakea punctulata & & & & & & & & & & & & & 2 & & & \\
\hline Blakea rosea & & 2 & 4 & & 2 & & 18 & & & 42 & & & & 30 & 63 & 316 \\
\hline Blakea schultzei & & 4 & & & & & & & & 9 & 21 & & & & & \\
\hline Blakea subconnata & & & & 2 & & & & & & & & & & & & \\
\hline Blakea sp $168 \mathrm{ZM}$ & & & & & & & & & 11 & & & & & & & \\
\hline Blakea sp $2348 \mathrm{HMC}$ & & & $7 \quad 1$ & 35 & & & & & & & & & & & & \\
\hline Blakea sp $3962 \mathrm{AP}$ & & & & & & & & & & & & & & & 3 & \\
\hline Blakea sp $4086 \mathrm{HMC}$ & & & & 21 & 5 & 18 & & & 19 & 8 & & & & & & \\
\hline Blakea sp $5627 \mathrm{HMC}$ & & & & & 2 & & 19 & & & & & & & & & \\
\hline Blakea sp 7164 HMC & & & & & & & & & & 1 & & & & & & \\
\hline Blakea sp 8839 HMC & & & & & $\varepsilon$ & & & & & & & & & & & \\
\hline Blakea sp 8978 HMC & & & & & 32 & & & & & & & & & & & \\
\hline Blakea sp $9300 \mathrm{HMC}$ & & & & & 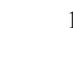 & & & & & & & & & & & \\
\hline Blakea sp $9303 \mathrm{HMC}$ & & & & & 3 & & & & & & & & & & & \\
\hline Blakeasp 16315 HMC & & & & & & & & & & 5 & & & & & & \\
\hline Blakeasp16375HMC & & & & & & & & & & & & & & 5 & 6 & 2 \\
\hline
\end{tabular}




\section{es}

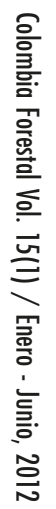

.

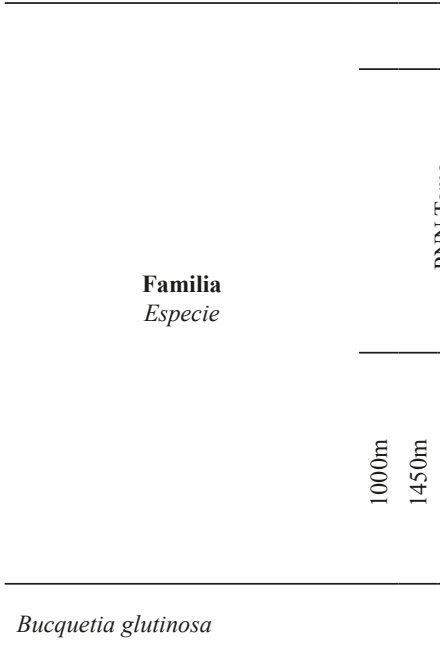

Centronia brachycera

Centronia haemantha

Chaetolepis lindeneana

Clidemia allardi

Clidemia ciliata

Clidemia cordata

Clidemia dimorphica

Clidemia epiphytica

11

Clidemia heterophylla

Clidemia novennervia

Clidemia pittieri

cf. Clidemia sp 7301 HMC

Clidemia sp 9007 HMC

Conostegia tenuifolia

3018
Vertiente Río Zulia

Vertiente Orientat de la Cordillera Orienta

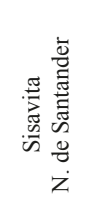

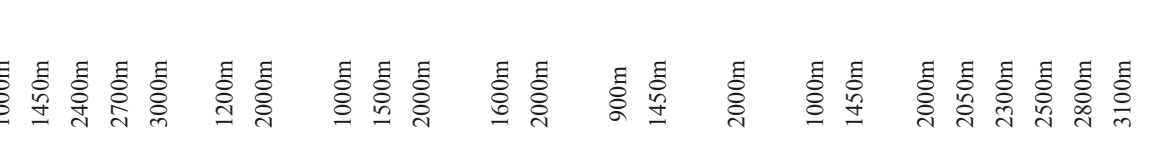

2039

18

1481

37

$\begin{array}{llll}45 & 8 & 78 & 7\end{array}$

$\begin{array}{llllll}48 & 31 & 7 & 40 & 9 & 7\end{array}$

22

$29 \quad 6$

\begin{tabular}{|c|c|c|c|c|}
\hline 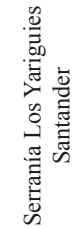 & 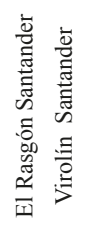 & 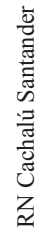 & 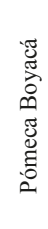 & 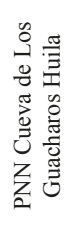 \\
\hline
\end{tabular}

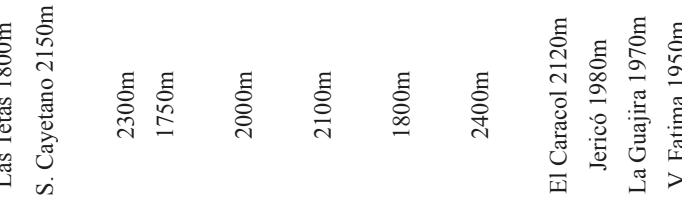

莺葛

40

23 


\begin{tabular}{|c|c|c|c|c|c|c|c|c|c|c|c|c|c|c|c|}
\hline \multirow{3}{*}{$\begin{array}{l}\text { Familia } \\
\text { Especie }\end{array}$} & \multicolumn{7}{|c|}{ Vertiente Oriental de la Cordillera Oriental } & \multirow{2}{*}{ 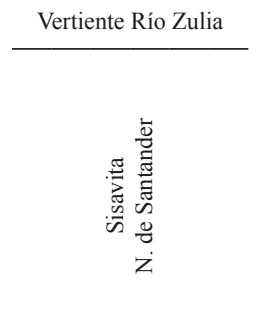 } & \multicolumn{7}{|c|}{ Vertiente Río Magdalena } \\
\hline & 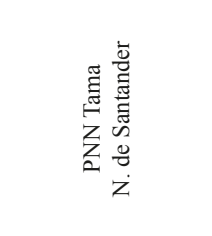 & 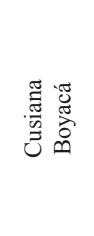 & 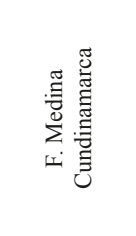 & 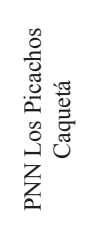 & 总 & 莺虽 & 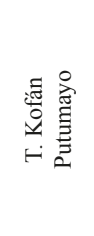 & & 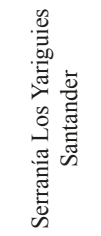 & 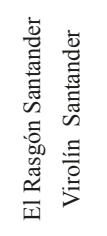 & 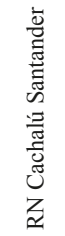 & 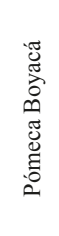 & 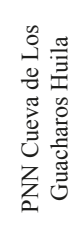 & 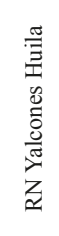 & 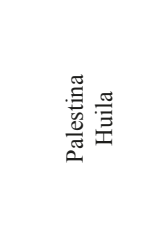 \\
\hline & 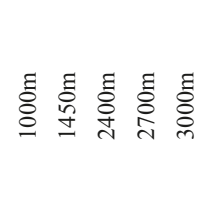 & 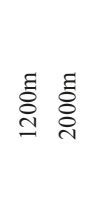 & ईี & 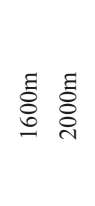 & 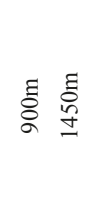 & छ్ & 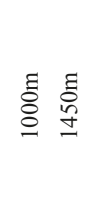 & 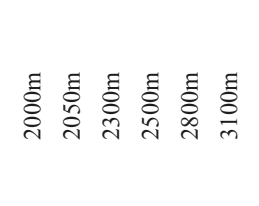 & 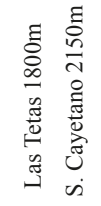 & 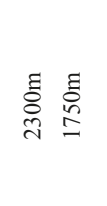 & క్̊̆ & 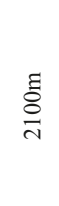 & $\underset{\Xi}{\Xi}$ & ह్ & 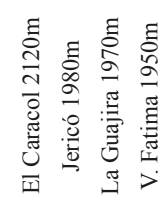 \\
\hline
\end{tabular}

\section{Ernestia sp 7234 HMC}

Graffenrieda colombiana

Graffenrieda cucullata

Graffenrieda gracilis

847

Graffenrieda intermedia

Graffenrieda santamartensis

16

3117

Graffenrieda uribei

Graffenrieda sp 3792 AP

Graffenrieda sp nov 7363 HMC $\quad 221$

Graffenrieda sp nov 16135 HMC

Graffenrieda sp 5668 HMC

Henriettea trachyphylla

27
13

$31 \quad 84$

10

$93 \quad 5 \quad 71$ 


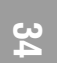

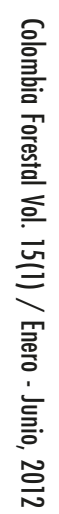

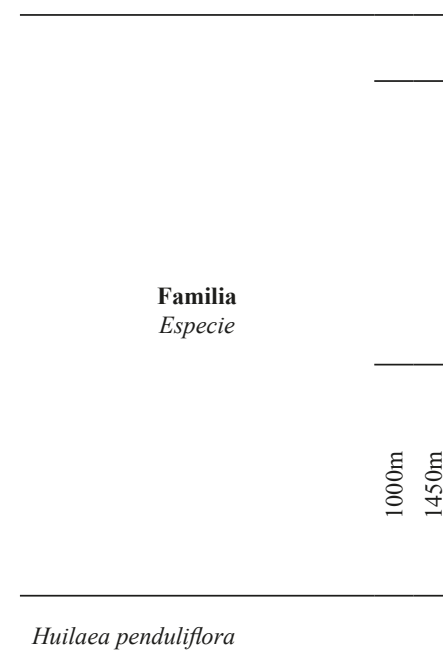

Leandra aristegera

Leandra chaetodon

Leandra longicoma

Leandra solenifera

Maieta guianensis

Meriania grandiden

Meriania hernandoi

Meriania hexamera

Meriania aff. hexamera

Meriania huilensis

Meriania longifolia

Meriania macrophylla

Meriania peltata

Meriania phlomioides

Meriania speciosa

24
Vertiente Oriental de la Cordillera Oriental

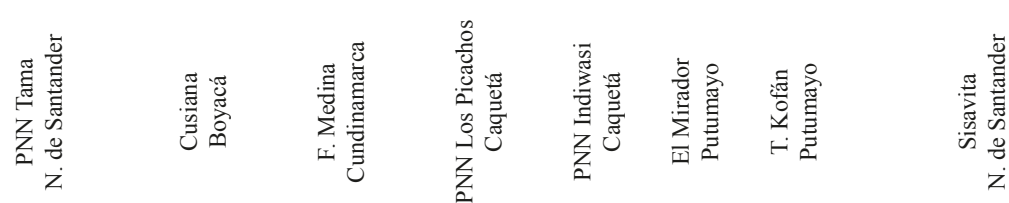

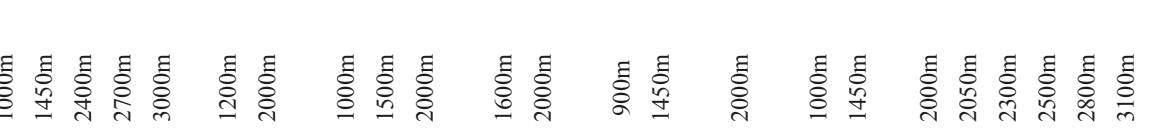

16

181

10

27

42
29
$18 \quad 2$

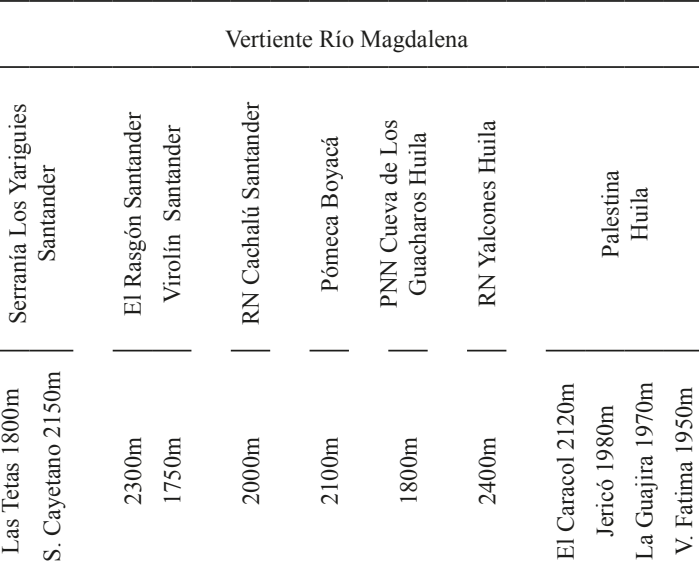

20

$13 \quad 6$

$\begin{array}{lllll}3 & 14 & 8 & 36 & 9\end{array}$ $\begin{array}{llll}17 & 1 & 15 & 1\end{array}$

18

21

24 


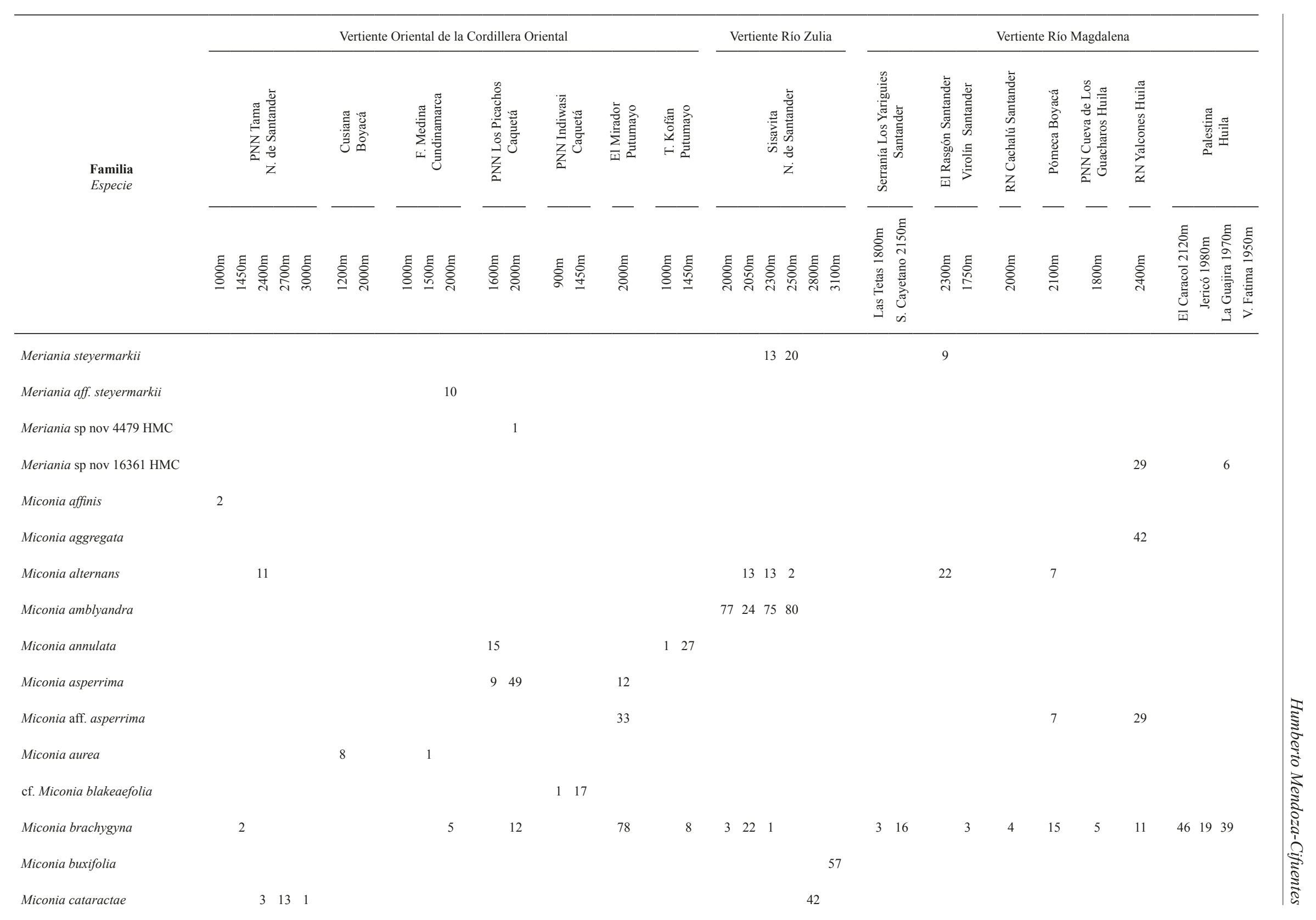




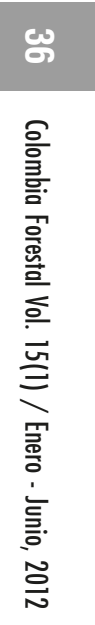

\begin{tabular}{|c|c|c|c|c|c|c|c|c|c|c|c|c|c|c|c|c|}
\hline \multirow[b]{2}{*}{$\begin{array}{l}\text { Familia } \\
\text { Especie }\end{array}$} & \multicolumn{7}{|c|}{ Vertiente Oriental de la Cordillera Oriental } & Vertiente Río Zulia & \multicolumn{8}{|c|}{ Vertiente Río Magdalena } \\
\hline & 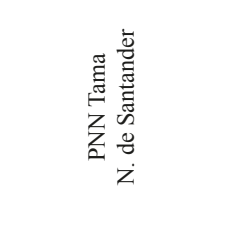 & 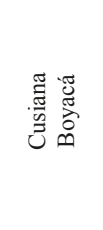 & 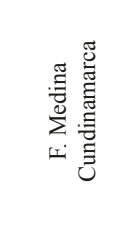 & 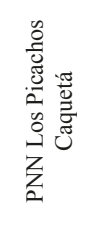 & 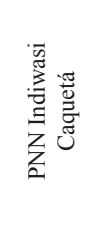 & 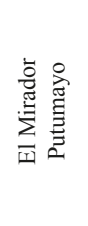 & 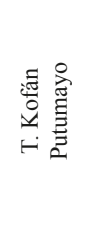 & 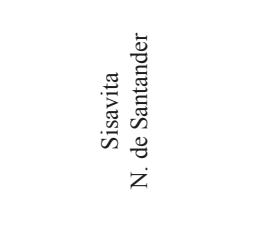 & 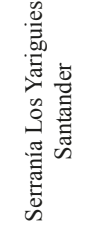 & 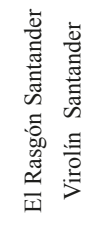 & 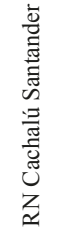 & 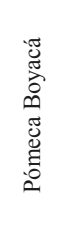 & 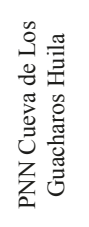 & 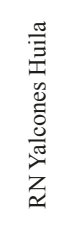 & 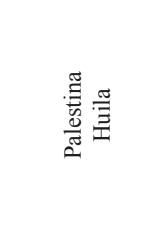 & \\
\hline Miconia caudata & 1 & 1 & 4 & & & & & & & & & & 3 & & 9 & \\
\hline Miconia centrodesma & & & & & 21 & & 10 & & & 3 & & & & & & \\
\hline Miconia coronata & & & & & & 13 & & & & & & & & & & \\
\hline Miconia aff. coronata & & & & & & & & & & & & 1 & 1 & & & \\
\hline Miconia costaricensis & & & & & & & & & & & & & & & 21 & 7 \\
\hline Miconia crassinevia & & & & & 9 & & 8 & & & & & & & & & \\
\hline Miconia cremophylla & & 2 & 5 & 42 & & & & 12 & & & & 9 & & & 5013 & \\
\hline Miconia cudinamrcensis & & & & & & & & & & & & & & 54 & 17 & \\
\hline Miconia denticulata & & & & & & & & & & & & & & 29 & & \\
\hline Miconia dichotoma & & & & & 16 & & 4263 & & & & & & 12 & & & 31 \\
\hline Miconia dodecandra & & & 5 & & & & & & & & & & & & & \\
\hline
\end{tabular}




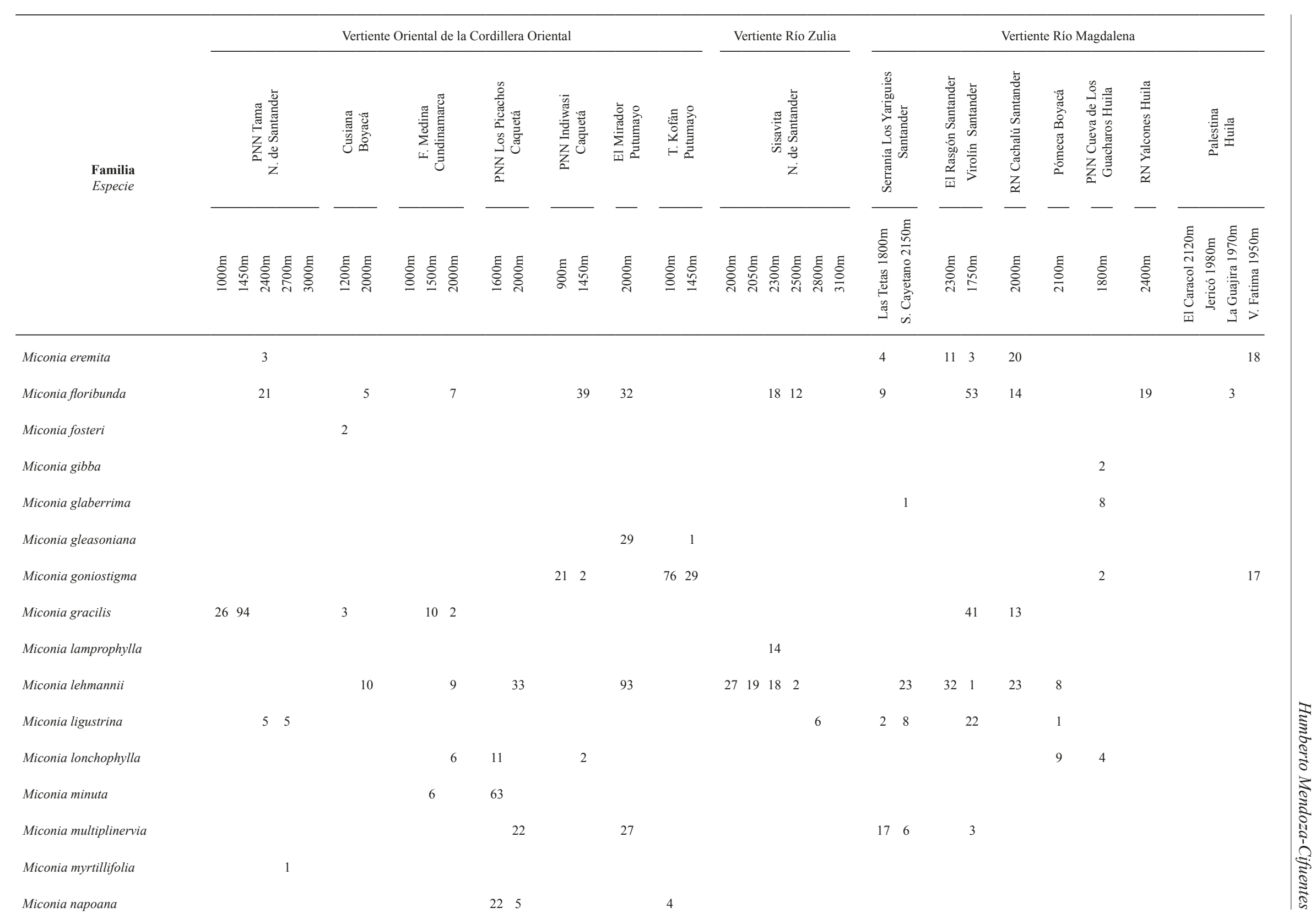




\begin{tabular}{|c|c|c|c|c|c|c|c|c|c|c|c|c|c|c|c|c|}
\hline \multirow{3}{*}{$\begin{array}{l}\text { Familia } \\
\text { Especie }\end{array}$} & \multicolumn{7}{|c|}{ Vertiente Oriental de la Cordillera Oriental } & \multirow{2}{*}{ 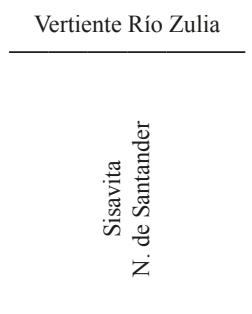 } & \multicolumn{8}{|c|}{ Vertiente Río Magdalena } \\
\hline & 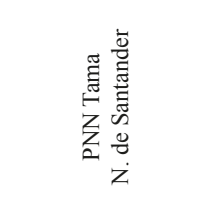 & 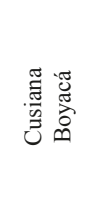 & 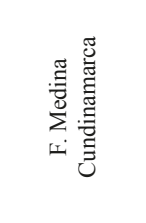 & 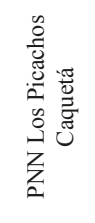 & 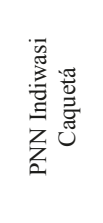 & 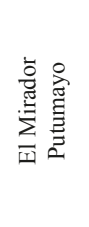 & 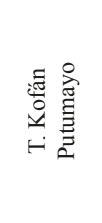 & & 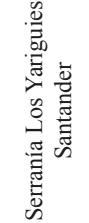 & 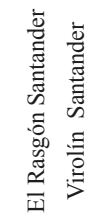 & 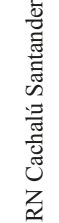 & 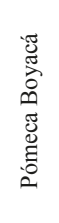 & 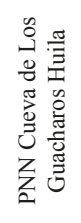 & 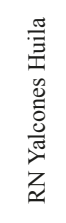 & 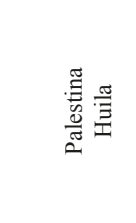 & \\
\hline & 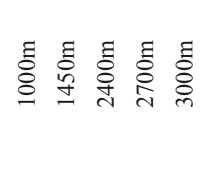 & 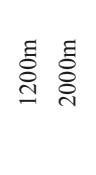 & 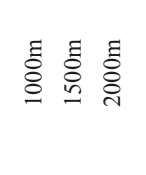 & 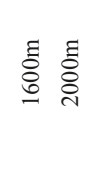 & 言 咅 & 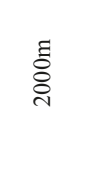 & 䇏 吉 & 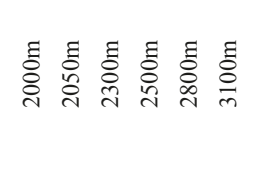 & 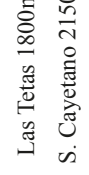 & 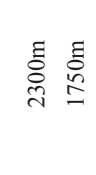 & ఫ్ڤ & 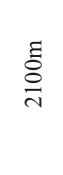 & $\begin{array}{l}\text { हू } \\
\stackrel{\Phi}{\sim}\end{array}$ & 吉 & 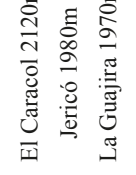 & 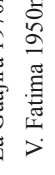 \\
\hline Miconia pennellii & & & & & & & & & 31 & & & & & & $59 \quad 28$ & \\
\hline Miconia aff. plena & & & & & & & & & 3341 & 44 & 8 & 3 & & & & \\
\hline Miconia pligeriana & & & & & 36 & & 243 & & & & & & & & & \\
\hline Miconia poecilantha & & & 4 & & 2 & & & & & & & & & & & \\
\hline Miconia prasina & & & & & & & 141 & & & & & & & & & \\
\hline Miconia aff. psycrophylla & & & & & & 47 & & & & & 10 & & & 7 & & \\
\hline Miconia pterocaulon & & & & & 31 & & 2 & & & & & & & & & \\
\hline Miconia pulvinata & $\begin{array}{ll}6 & 4\end{array}$ & & 10 & & & & & & & & & & & & & \\
\hline Miconia punctata & 2244 & & & & 577 & & & & & & & & & & 1 & 9 \\
\hline Miconia resima & & & & & & 28 & & & 62 & & & 8 & 21 & 35 & 397240 & 18 \\
\hline Miconia reduscens & $\begin{array}{ll}9 & 10\end{array}$ & & & & & & & & 29 & & & & & & & \\
\hline Miconia smaragdina & & 7 & $5 \quad 1$ & 1 & & & & & 15 & & 39 & & & & 2 & 3 \\
\hline Miconia spatellophora & & & & 13 & 37 & 45 & 4121 & & & & & & 4 & 21 & 52984 & 42 \\
\hline Miconia splendens & & & & & 9 & & & & & & & & & & & \\
\hline Miconia stipularis & & & & & & & & & & & & & & 1 & & \\
\hline Miconia summa & 9 & & & & & & & & & & & & & & & \\
\hline
\end{tabular}




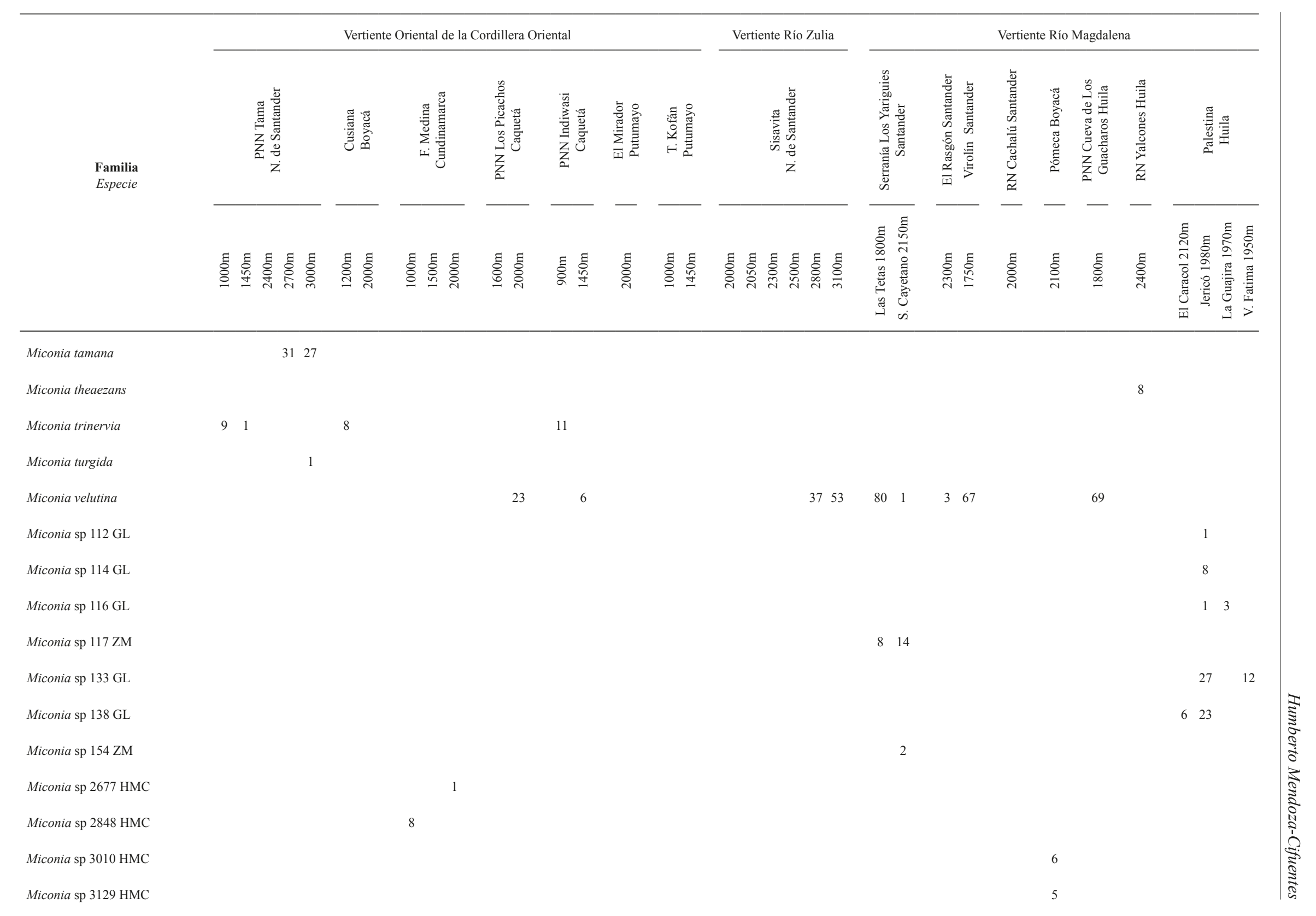




\section{t}

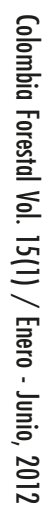

Famila

Especie

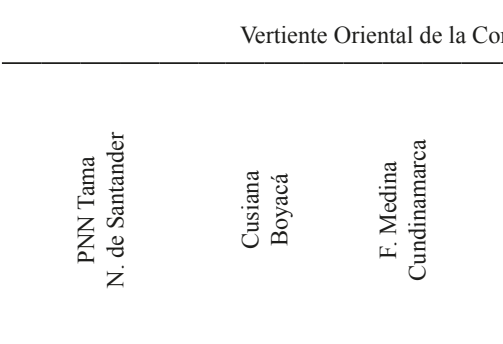

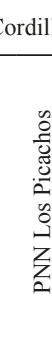

Vertiente Río Zulia

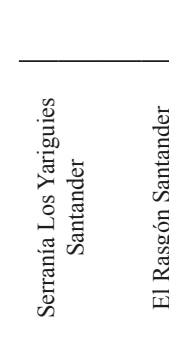

Vertiente Río Magdalena

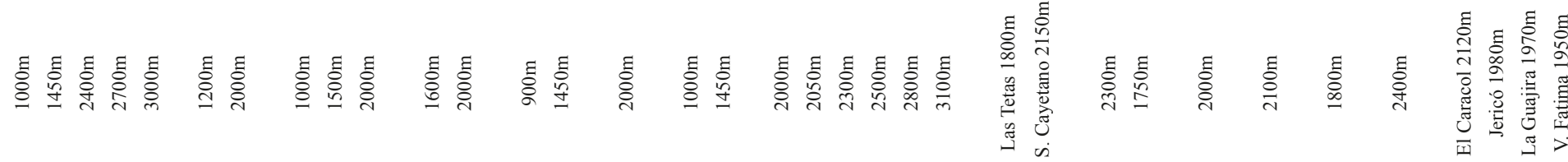

Miconia sp 3136 HMC

Miconia sp 4027 HMC

Miconia sp 4048 AP

Miconia sp 4052 AP

Miconia sp 4053 AP

Miconia sp 4055 HMC

Miconia sp 4081 AP

Miconia sp 4351 HMC

Miconia sp 4435 HMC

Miconia sp 4462b HMC

Miconia sp 4475 HMC

Miconia sp 5580 HMC

Miconia sp 5612 HMC

Miconia sp 5740 HMC

$\begin{array}{cccc} & 53 & & 6 \\ 1 & 37 & 1 \\ & 3 & \\ & 16 & \end{array}$

$27 \quad 57$ 


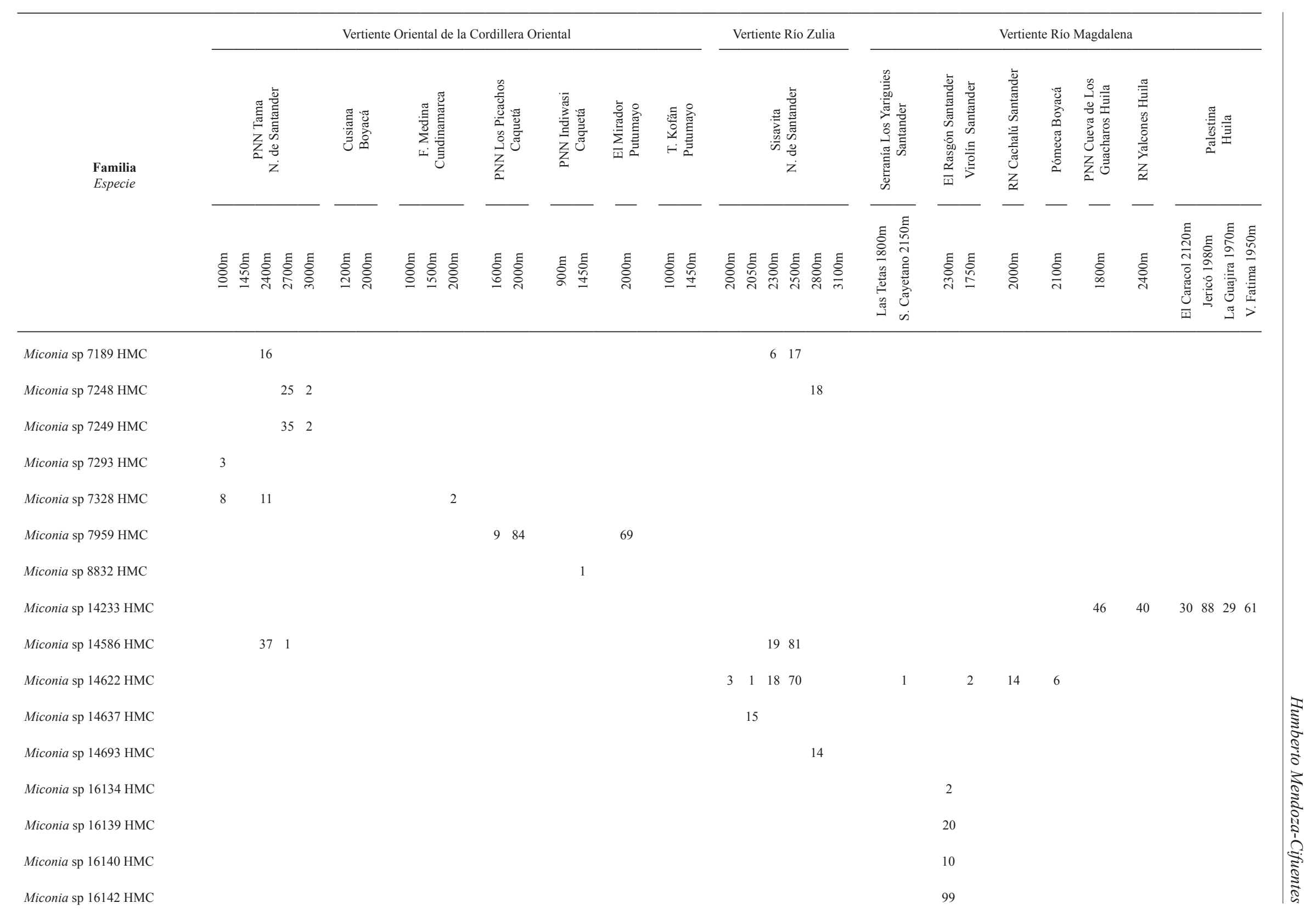




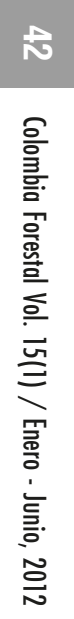

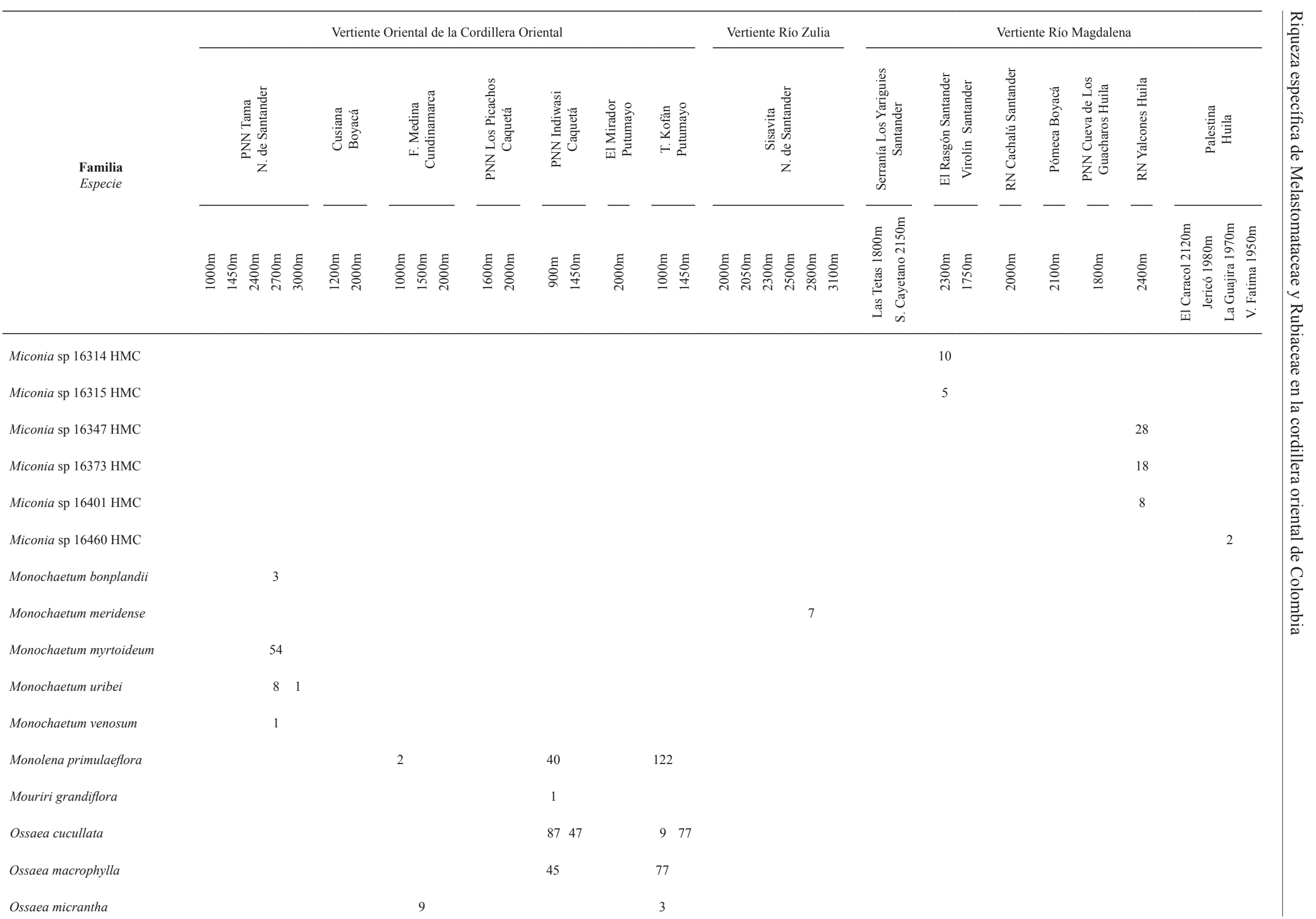




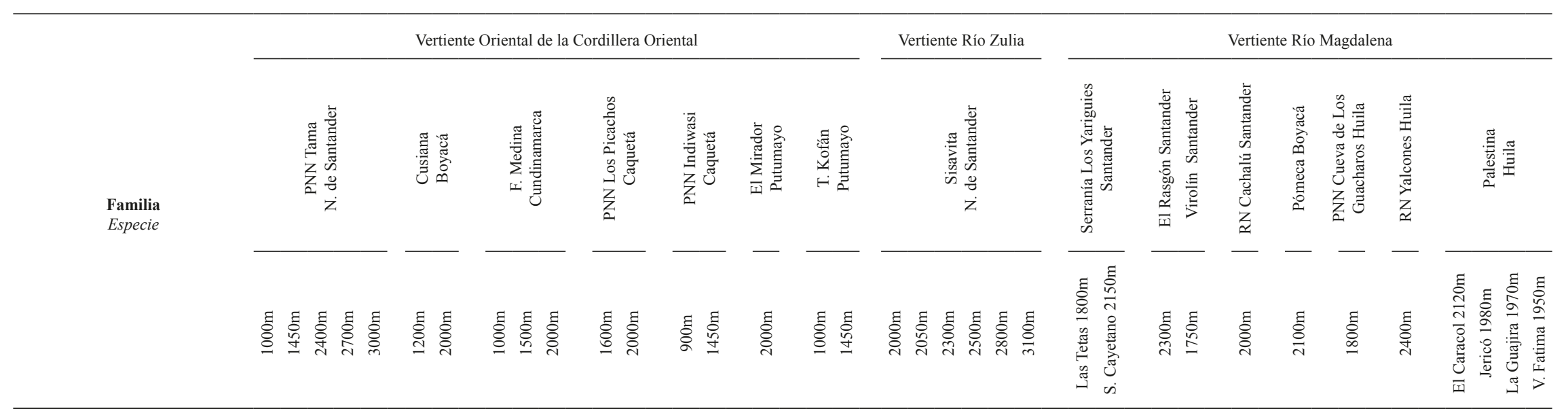

Ossaea robusta

Pachyanthus corymbiferu

Tibouchina grossa

Tibouchina lepidota

Tococa guianensis

Tococa platyphylla

Topobea sp 7017b HMC

Topobea sp 8983 HMC

Triolena agrmioides

Triolena cf. allardi

Wurdastom cuatrecasasi

Indet sp 3244 HMC

Indet sp 4035 HMC

Indet sp 5638 HMC

Indet sp 7039 HMC

Indet sp 7146 HMC
1081

$22 \quad 2$

14
2

19

9

$31 \quad 19$

21 


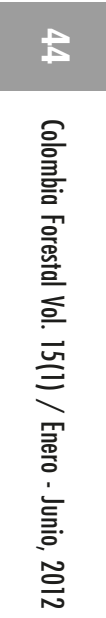

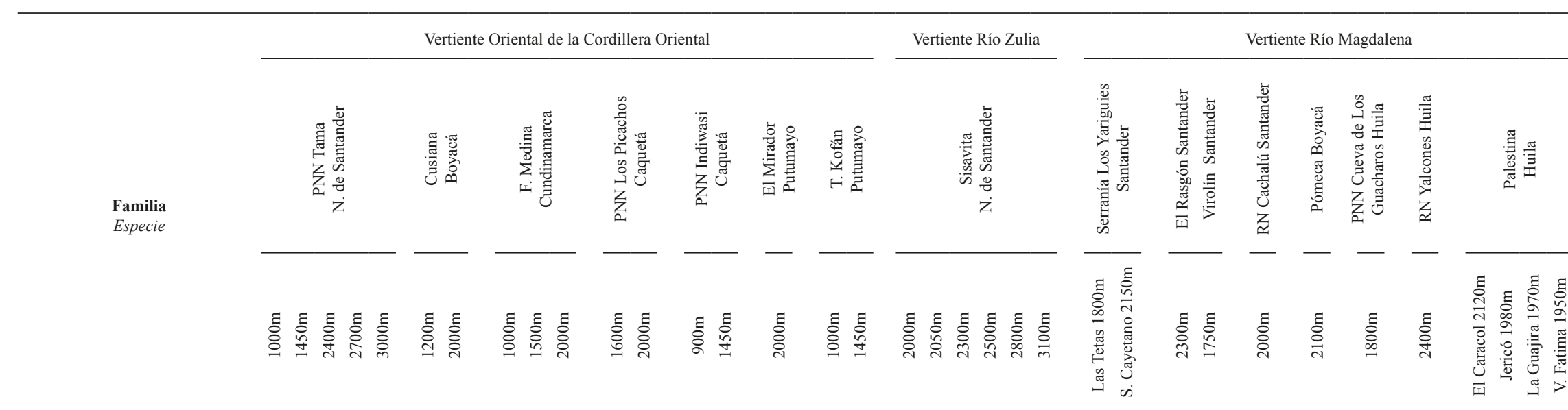

\begin{tabular}{ll}
\hline Indet sp 7197a HMC & 2 \\
\hline RUBIACEAE &
\end{tabular}

\section{RUBIACEAE}

Alibertia clavifora

Alibertia hispida

Alseis sp $5484 \mathrm{HMC}$

Amphydasia ambigua

Arachnothryx reflexa

Arcytophyllum nitidum

Bathysa bracteosa

Chimarrhis turbinata

Chimarrhis sp $124 \mathrm{ZM}$

Chiococa alba

Chomelia barbellata

Chomelia sp 5574 HMC

Ciliosemina pedunculata

Cinchona henlean
$8 \quad 8$
1

31

$\begin{array}{llll}24 & 1 & 28 & 12\end{array}$

1289

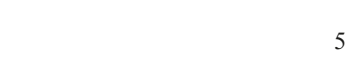

$2 \quad 8$

5

2




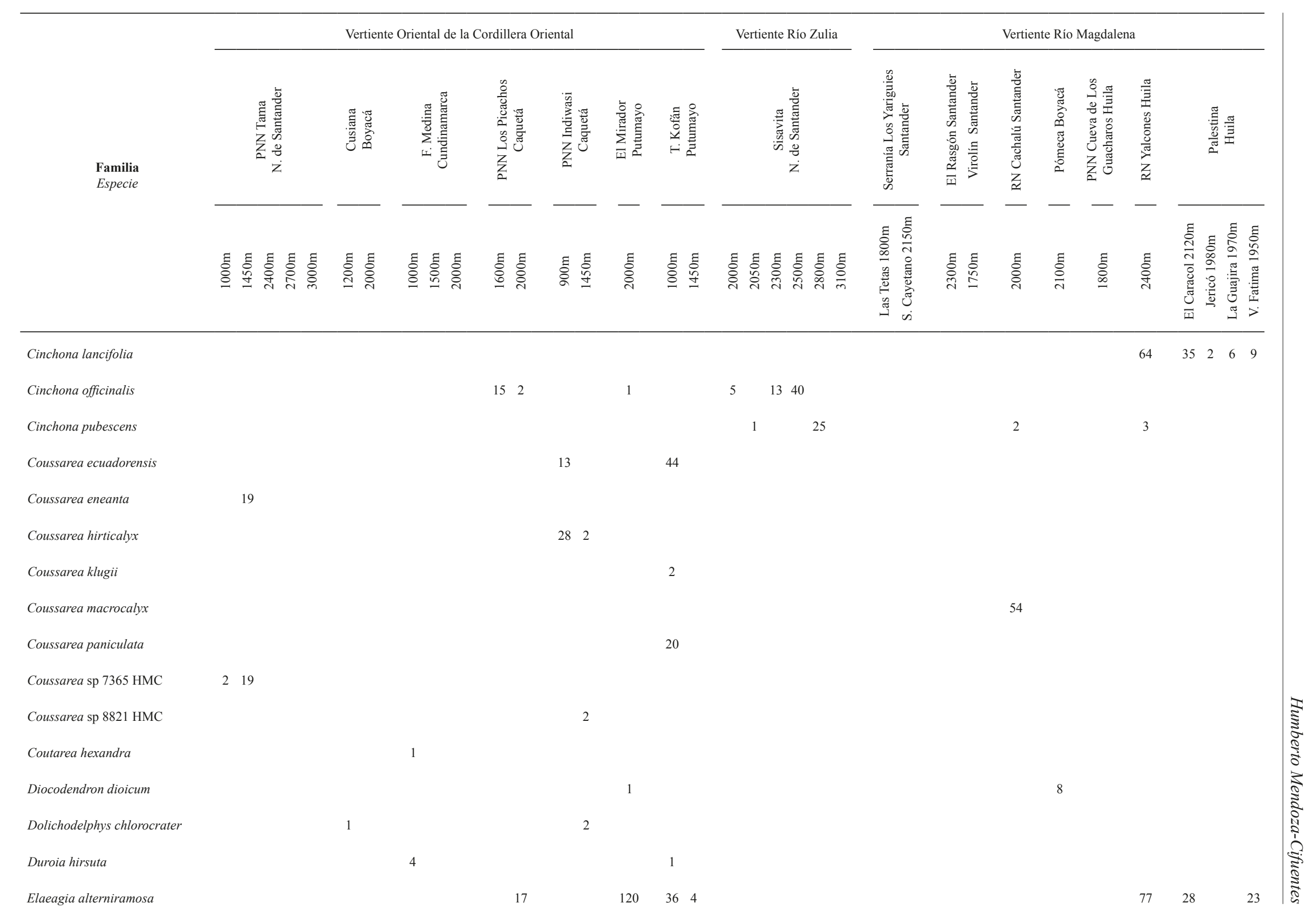




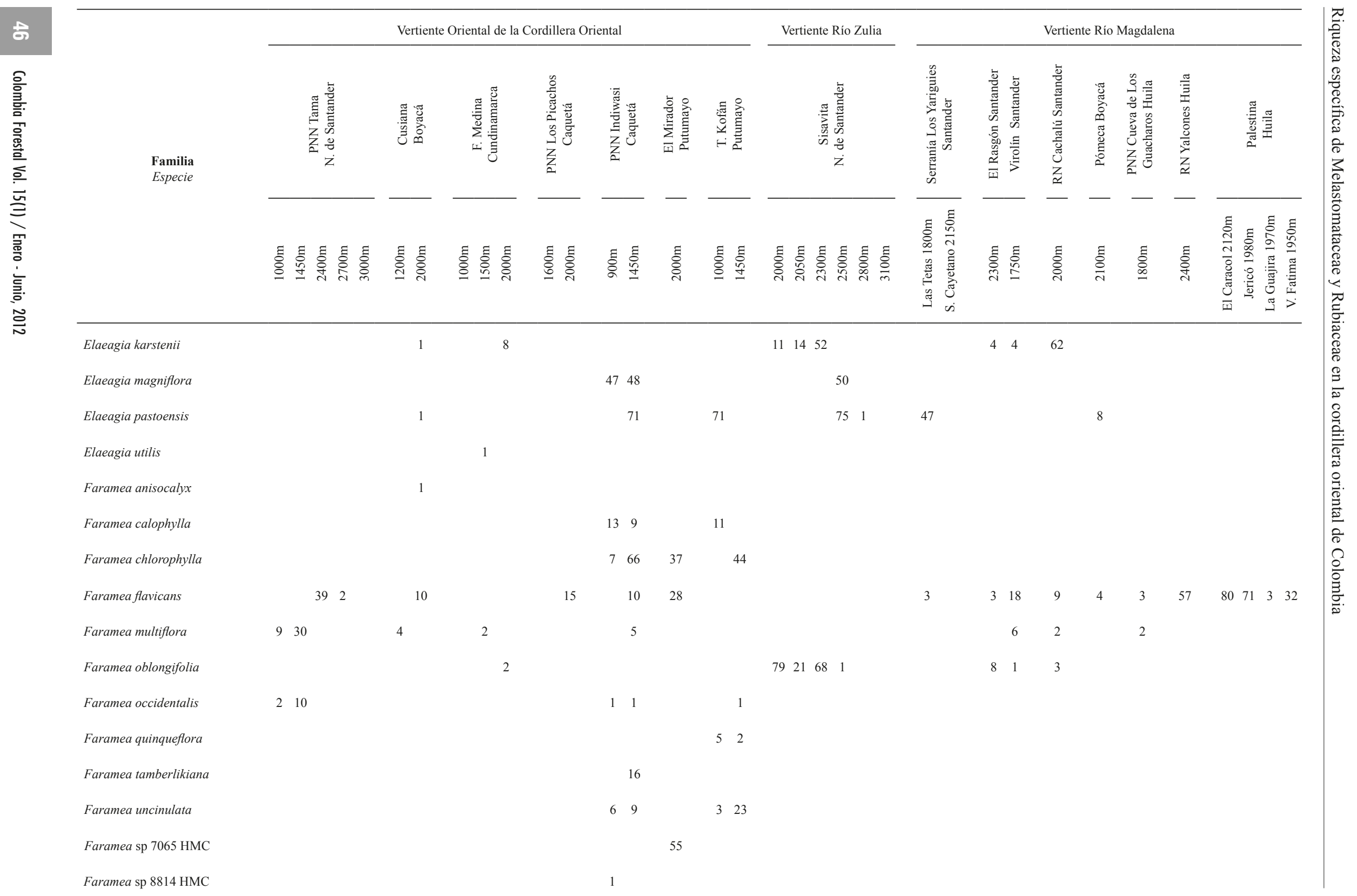




\begin{tabular}{|c|c|c|c|c|c|c|c|c|c|c|c|c|c|c|c|}
\hline \multirow{3}{*}{$\begin{array}{l}\text { Familia } \\
\text { Especie }\end{array}$} & \multicolumn{7}{|c|}{ Vertiente Oriental de la Cordillera Oriental } & Vertiente Río Zulia & \multicolumn{7}{|c|}{ Vertiente Río Magdalena } \\
\hline & 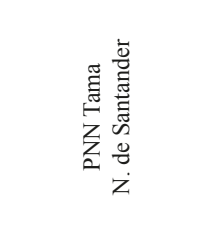 & 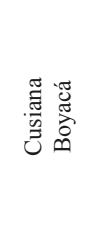 & 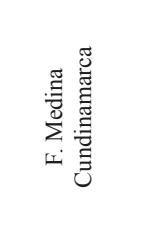 & 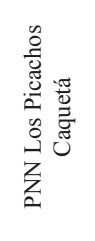 & 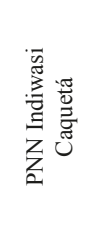 & 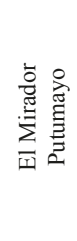 & 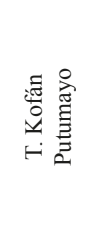 & 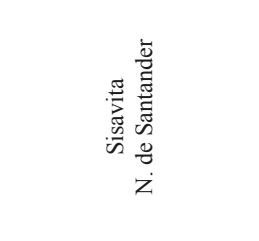 & 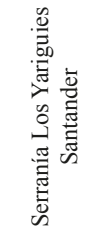 & 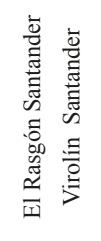 & 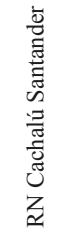 & 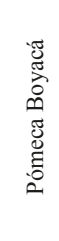 & 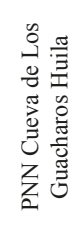 & 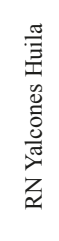 & 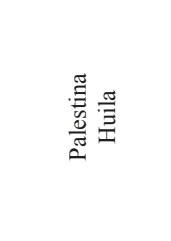 \\
\hline & 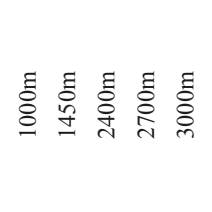 & ईే ڤ్ & हี छ & 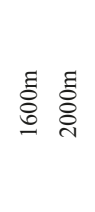 & క్ & छ్ڤ & 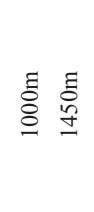 & 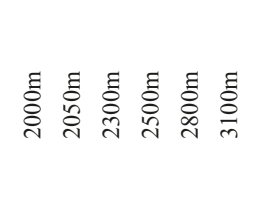 & 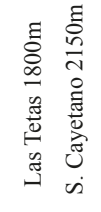 & ప్ & క్ & $\underset{\Xi}{\Xi}$ & $\underset{\Phi}{\Xi}$ & ฐ్ & 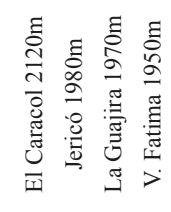 \\
\hline
\end{tabular}

Ferdinandusa sp 9281 HMC

Galium hypocarpium

12

Gonzalagunia colombiana

\section{Guettarda crispiflora}

Guettarda tournefortiopsis

Hillia macrophylla

Hillia parasitica

Hippotis albiflora

Hippotis sp 14746 HMC

Hoffmannia angustifolia

Hoffmannia pauciflora

Hoffmannia sp 14521 HMC

Hoffmannia sp 16151 HMC

Ixora panurensis

Ixora sp 6782 HMC

Ixora sp 8939 HMC
32
145

7

13

$\begin{array}{lllll}2 & 4 & 1 & 7 & 2\end{array}$

3

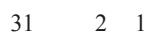

$\begin{array}{lll}7 & 2 & 3\end{array}$ 


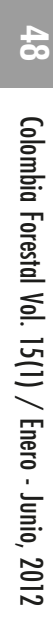

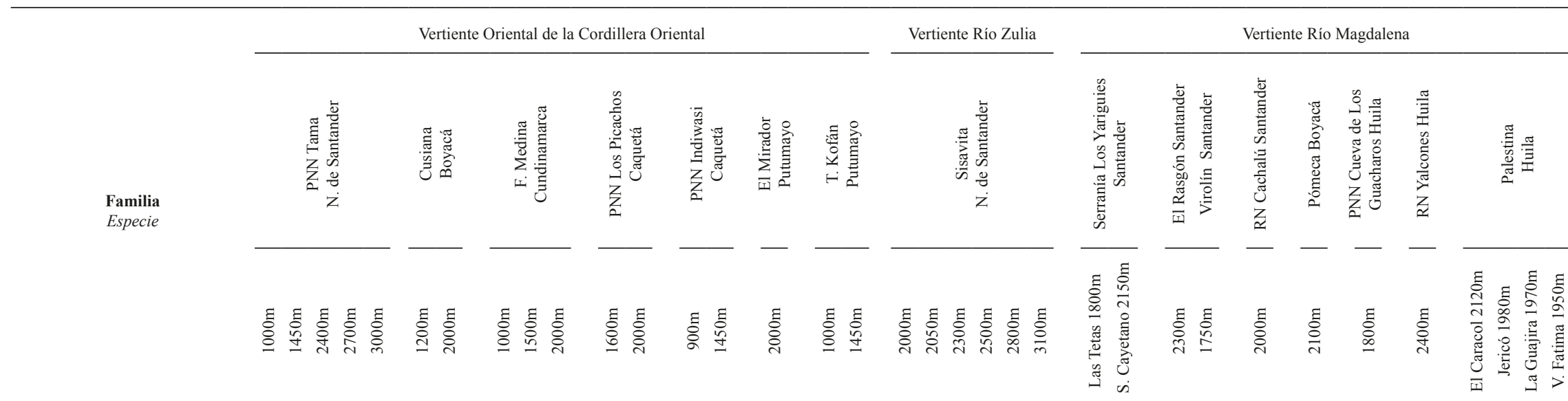

\section{Joosia umbellifera \\ Kutchubaea semisericea}

210

Ladenbergia macrocarpa

$\begin{array}{ll}7 & 1\end{array}$

Ladenbergia magnifolia

Ladenbergia oblongifolia

Ladenbergia undata

Ladenbergia sp 8922 HMC

Malanea sp 2870 HMC

Manettia reclinata

Manettia suratensis

Manettia sp 14567 HMC

Nertera granadensis

Notopleura epiphytica

Notopleura guadalupensis

11

$33 \quad 27$

235

12

1

Notopleura leucantha

Notopleura longipedunculata $\quad 2$
527

22

$627 \quad 5 \quad 75$

$72 \quad 3 \quad 5$

5
-30

$66 \quad 5$

$\begin{array}{llllll}1 & 9 & 5 & 5 & 3 & 9\end{array}$




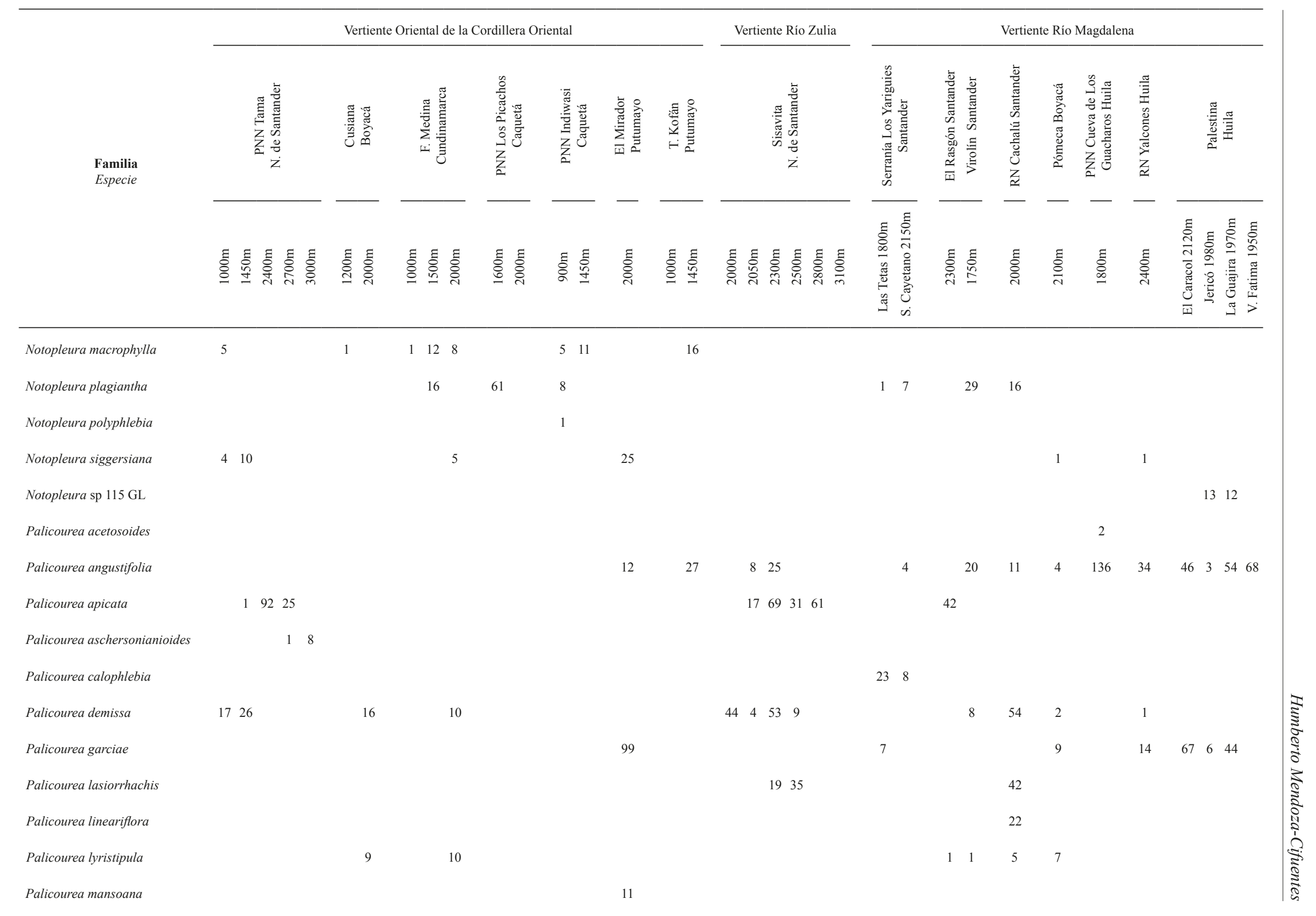




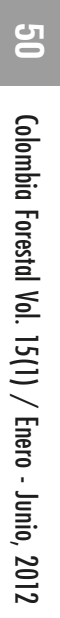

\begin{tabular}{|c|c|c|c|c|c|c|c|c|c|c|c|c|c|c|c|}
\hline \multirow{3}{*}{$\begin{array}{c}\text { Familia } \\
\text { Especie }\end{array}$} & \multicolumn{7}{|c|}{ Vertiente Oriental de la Cordillera Oriental } & \multirow{2}{*}{ 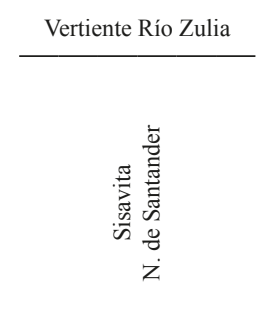 } & \multicolumn{7}{|c|}{ Vertiente Río Magdalena } \\
\hline & 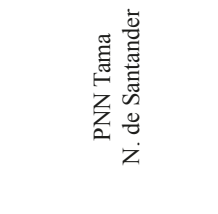 & 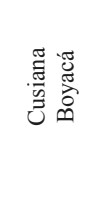 & 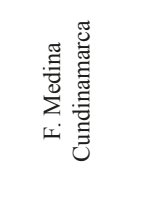 & 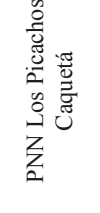 & 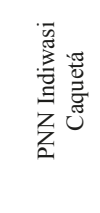 & 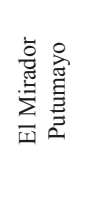 & 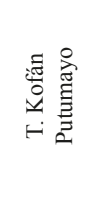 & & 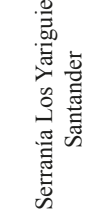 & 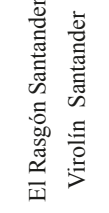 & 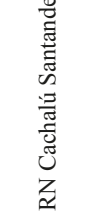 & 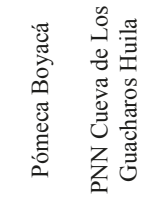 & 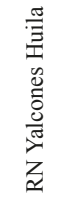 & & 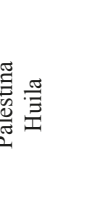 \\
\hline & 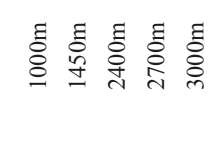 & 言 & 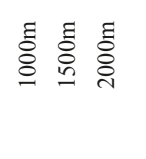 & 言 & 镸痋 & 言 & 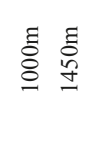 & 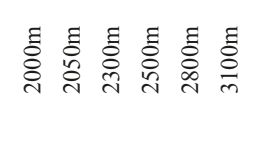 & 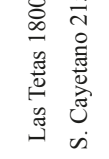 & 镸 & 言 & 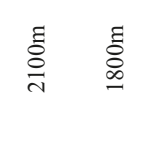 & 或 & & 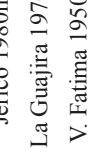 \\
\hline Palicourea myrtifolia & & & 3 & 1 & & & & 223949 & & & & & 9 & & 29 \\
\hline Palicourea ovalis & & & & & & 32 & & & & & & & & & \\
\hline Palicourea pyramidalis & & & & 8 & 35 & & & & & & & & 26 & 356 & 51814 \\
\hline Palicourea semirasa & 5 & 2 & 6 & & & & & & & & & & & & \\
\hline Palicourea stipularis & & & & & & & & & & & & & 64 & 42 & 48 \\
\hline Palicourea subulata & & & & & 111 & & 25 & & & & & & & & \\
\hline Palicourea tamaensis & 1 & & & & & & & 1 & & & & & & & \\
\hline Palicourea thyrsiffora & & 4 & 9 & & & & & & & & & & & & \\
\hline Palicourea tunjaensis & & 5 & & & & & & & 11 & & & & & & \\
\hline Palicourea vagans & & & & & & & & & & 58 & 10 & 8 & & & \\
\hline Palicourea sp $152 \mathrm{ZM}$ & & & & & & & & & 5 & & & & & & \\
\hline Palicourea sp $3187 \mathrm{HMC}$ & & 2 & & & & & & & & & & & & & \\
\hline Palicourea sp $3187 \mathrm{HMC}$ & & & & & & & & & & & & & & & \\
\hline Palicourea sp $3817 \mathrm{AP}$ & & & & & & & & & & & & & & & 20 \\
\hline Palicourea sp $7185 \mathrm{HMC}$ & 134 & & & & & & & 28 & & & & & & & \\
\hline Palicourea sp $7377 \mathrm{HMC}$ & 1 & & & & & & & & & & & & & & \\
\hline Palicourrea sp $8816 \mathrm{HMC}$ & & & & & $\begin{array}{lll}1 & 118\end{array}$ & & & & & & & & & & \\
\hline
\end{tabular}




\begin{tabular}{|c|c|c|c|c|c|c|c|c|c|c|c|c|c|c|c|}
\hline \multirow{3}{*}{$\begin{array}{l}\text { Familia } \\
\text { Especie }\end{array}$} & \multicolumn{7}{|c|}{ Vertiente Oriental de la Cordillera Oriental } & \multirow{2}{*}{ 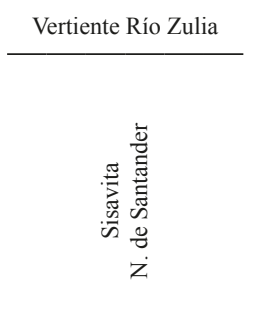 } & \multicolumn{7}{|c|}{ Vertiente Río Magdalena } \\
\hline & 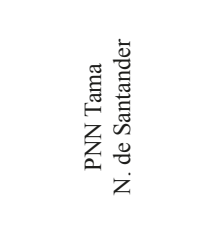 & 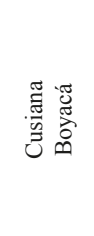 & 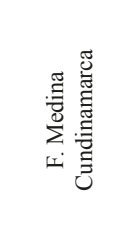 & 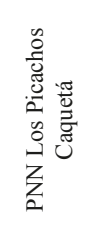 & 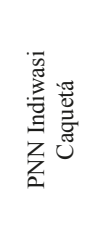 & 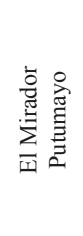 & 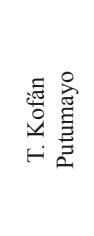 & & 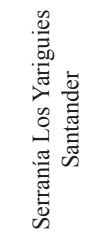 & 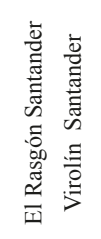 & 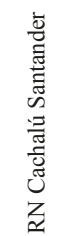 & 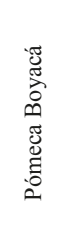 & 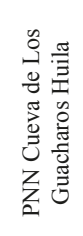 & 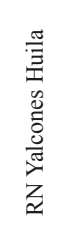 & 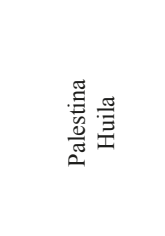 \\
\hline & 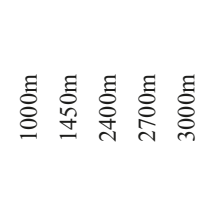 & క్ี & 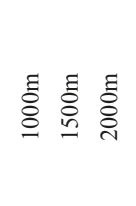 & 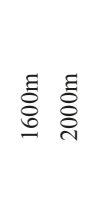 & 志 志 & छ్ڤ & క్ & 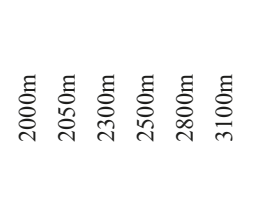 & 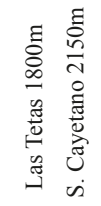 & 志 & छั & 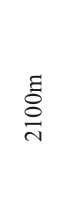 & 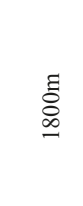 & 吉 & 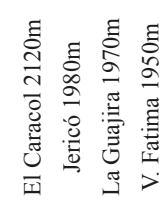 \\
\hline
\end{tabular}

Palicourea sp 8819 HMC

Palicourea sp $16360 \mathrm{HMC}$

\section{Pentagonia parvifora}

Posoqueria coriacea

Psychotria acuminata

Psychotria alba

Psychotria allenii

\section{Psychotria amito}

Psychotria aschersoniana

Psychotria aubletiana

Psychotria aff. aubletiana

Psychotria berteriana

Psychotria brachyata

Psychotria brachybotrya

Psychotria caerulea

Psychotria capitata

Psychotria cauligera

2

$\begin{array}{lllllll}48 & 5 & 4 & 16 & 20 & 32 & 19\end{array}$

$17 \quad 5$

41

$21 \quad 17 \quad 14$

8855

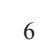

$4511974 \quad 47$
$4 \quad 58$

$5 \quad 25$
10

$25 \quad 12 \quad 32 \quad 2$

$\begin{array}{llll}37 & 3 & 1 & 46\end{array}$ 


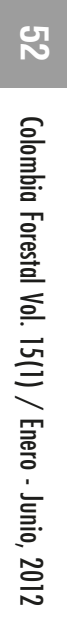

\begin{tabular}{|c|c|c|c|c|c|c|c|c|c|c|c|c|c|c|c|}
\hline \multirow{3}{*}{$\begin{array}{l}\text { Familia } \\
\text { Especie }\end{array}$} & \multicolumn{7}{|c|}{ Vertiente Oriental de la Cordillera Oriental } & Vertiente Río Zulia & \multicolumn{7}{|c|}{ Vertiente Río Magdalena } \\
\hline & 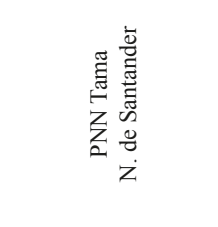 & 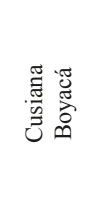 & 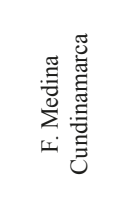 & 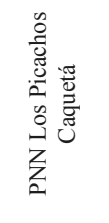 & 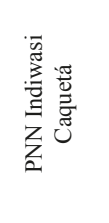 & 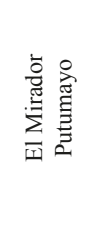 & 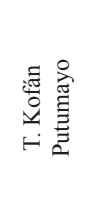 & 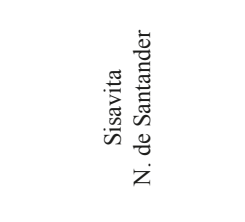 & 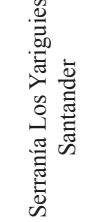 & 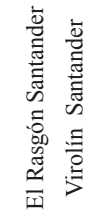 & 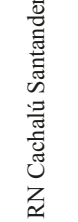 & 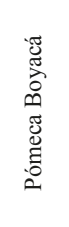 & 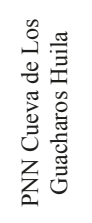 & 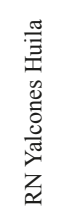 & 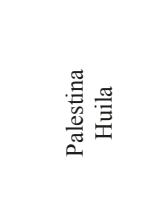 \\
\hline & 言镸镸高高 & 言 & 言 言 言 & 言镸 & 言镸 & 言 & 言镸 & 言高高高 & 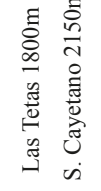 & 㡲言 & 高 & $\underset{\frac{\Xi}{\sigma}}{\frac{\Xi}{\sim}}$ & 咅 & 䂸 & 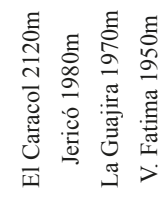 \\
\hline Psychotria cenepensis & & & & & & & 683 & & & & & & & & \\
\hline Psychotria cincta & & & & & & & & & 1 & & & & & & \\
\hline Psychotria deffexa & 23 & & & & & & 9527 & & 1 & & & & & & \\
\hline Psychotria erythrocephala & & & & & & & & 6 & 2 & 53 & 28 & & 7 & & \\
\hline Psychotria flaviffora & 2361 & & & & & & 30 & & & & & & & & \\
\hline Psychotria gentryi & & & & & & & 8 & & & & & & & & \\
\hline Psychotria lindenii & & & & & 16 & & & & & & & & & & \\
\hline Psychotria longirostris & & & & & & & 772 & $70 \quad 1$ & 2 & & & & & & \\
\hline Psychotria Iucentifolia & & & 2 & & & & 3 & & & & 16 & & & & \\
\hline Psychotria officinalis & 4 & 6 & 3 & & 714 & & 8113 & & & & & & & & \\
\hline Psychortia ownbeyi & & & & & & & 40 & & & & & & & & \\
\hline Psychotria pilosa & & & & & 3 & & 1 & & & & & & & & \\
\hline Psychotria poeppigiana & 1 & & & & 1925 & & 13 & & 2 & & & & & & \\
\hline Psychotria remota & & & & & & & 1 & & & & & & & & \\
\hline Psychotria rufframea & & 3 & & & & 1 & & 24143222 & & 36 & 43 & 1 & 2 & 5 & 3 \\
\hline Psychotria tinctoria & & & & & 21 & & 518 & & & & & & & & \\
\hline Psychotria trichotoma & 5 & & & & & & & & & & & & & & \\
\hline
\end{tabular}




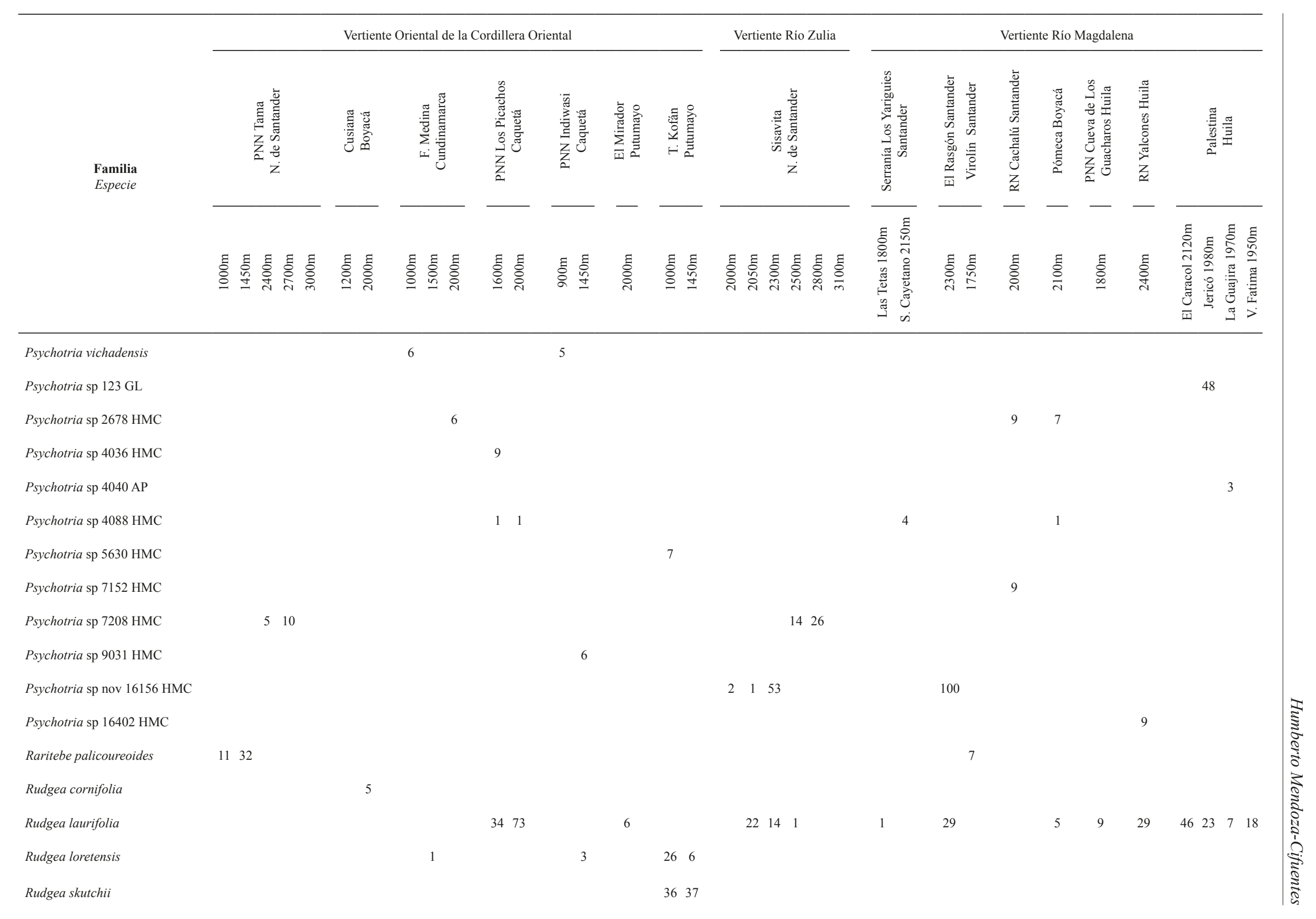




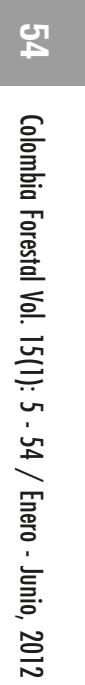

\begin{tabular}{|c|c|c|c|c|c|c|c|c|c|c|c|c|c|c|c|}
\hline \multirow{3}{*}{$\begin{array}{l}\text { Familia } \\
\text { Especie }\end{array}$} & \multicolumn{7}{|c|}{ Vertiente Oriental de la Cordillera Oriental } & \multirow{2}{*}{ 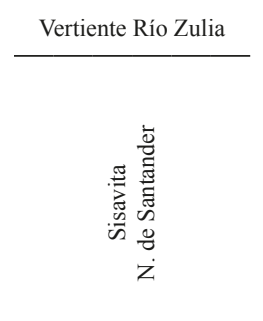 } & \multicolumn{7}{|c|}{ Vertiente Río Magdalena } \\
\hline & 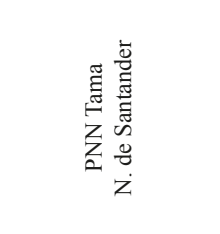 & 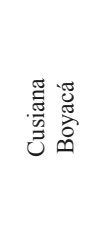 & 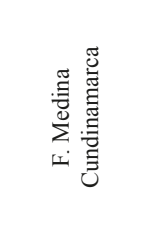 & 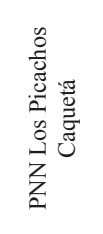 & 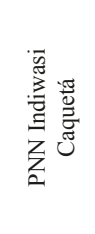 & 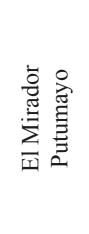 & 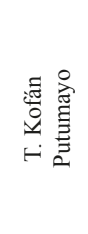 & & 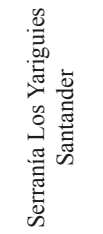 & 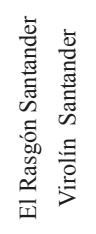 & 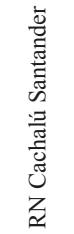 & 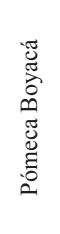 & 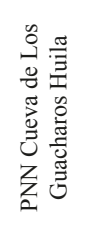 & 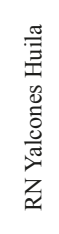 & 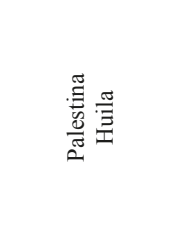 \\
\hline & 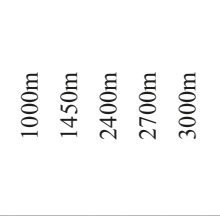 & हี & 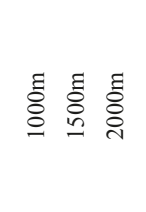 & 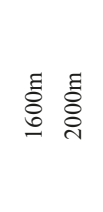 & 咅言 & 离 & 䓂 咅 & 空 空 & 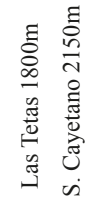 & 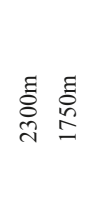 & క్ & 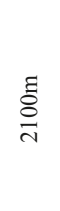 & 䓂 & 蒿 & 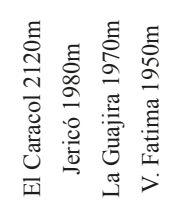 \\
\hline Rudgea sp 5673 HMC & & & & & $4 \quad 1$ & & 3527 & & & & & & & & \\
\hline Rustia alba & & & & 28 & 1 & & & & & & & & & & \\
\hline Rustia thibaudoides & & & & & & & 126 & & & & & & & & \\
\hline Sabicea glomerata & & & & & & & & & & & 1 & & & & \\
\hline Sabicea panamensis & 111 & & & 2 & 2 & & & & & 3 & & & 1 & & \\
\hline Sabicea pearcei & $9 \quad 1$ & & & & & & & & & & & & & & \\
\hline Schradera andina & & & & & 2678 & 22 & 102 & & 4621 & 11 & & & & & \\
\hline Simira maxonii & & 3 & & & & & & & & & & & & & \\
\hline Simira sp 7332 HMC & 2 & & & & & & & & & & & & & & \\
\hline Sphinctanthus maculatus & & & & & 1 & & & & & & & & & & \\
\hline cf. Tocoyena costanensis & & & & & & 4 & & & & & 4 & 6 & 2 & 25 & \\
\hline Warcsewiczia coccinea & & 4 & 4 & & 32 & & 11 & & & & & & & & \\
\hline Indet sp $3765 \mathrm{HMC}$ & & 1 & & & & & & & & & & & & & \\
\hline indet Gardenidae sp 5656 HMC & & & & & & & 16 & & & & & & & & \\
\hline indetGardenidae sp 7385 HMC & 2 & & & & & & & & & & & & & & \\
\hline
\end{tabular}

